\title{
Increasing access to safe abortion in rural Maharashtra: Outcomes of a comprehensive abortion care model
}

Shireen J. Jejeebhoy Population Council

A.J. Francis Zavier

Population Council

Rajib Acharya

Population Council

Shveta Kalyanwala

Population Council

Follow this and additional works at: https://knowledgecommons.popcouncil.org/departments_sbsr-rh

Part of the Demography, Population, and Ecology Commons, Family, Life Course, and Society Commons, Health Policy Commons, International Public Health Commons, Public Health Education and Promotion Commons, and the Women's Health Commons How does access to this work benefit you? Let us know!

\section{Recommended Citation}

Jejeebhoy, Shireen J., A.J. Francis Zavier, Rajib Acharya, and Shveta Kalyanwala. 2011. "Increasing access to safe abortion in rural Maharashtra: Outcomes of a comprehensive abortion care model." New Delhi: Population Council. 

The Consortium for Safe Abortions in India, comprising Ipas (Coordinating Partner), Action Research and Training for Health (ARTH), the Centre for Enquiry into Health and Allied Themes (CEHAT), the Family Planning Association of India (FPAI), Federation of Obstetric and Gynaecological Societies of India (FOGSI), International Maternal and Child Health (IMCH)-Uppsala University, the Population Council and the Society of Midwives, India (SOMI), was established with the goal of increasing the ability of rural women to acquire accessible and high quality abortion services. One of its key activities was to develop and implement a comprehensive and evidence-based abortion care model for rural women that addressed both facility-based and community-based barriers to safe abortion, that focused on enabling public sector sites to offer comprehensive abortion care services and simultaneously, to build awareness at woman- and community-levels about the legality of abortion and the availability of safe abortion services in the public sector. The model was developed and implemented by Consortium partner Ipas, in one district of Maharashtra, namely, Aurangabad. The Population Council conducted an assessment of the effectiveness of this model in improving the availability and quality of abortion services in public sector facilities, and women's awareness and experiences with regard to abortion services. This report presents a description of the model and the findings of the assessment.

For additional copies of this report, please contact:

Population Council

Zone 5-A, Ground Floor

India Habitat Centre

Lodi Road

New Delhi 110003

Phone: 011-2464 2901/02

email: info.india@popcouncil.org

Web site: http://www.popcouncil.org/asia/india.html

The Population Council is an international, non-profit, non-governmental organisation that seeks to improve the well-being and reproductive health of current and future generations around the world and to help achieve a humane, equitable and sustainable balance between people and resources. The Council conducts biomedical, social science and public health research, and helps build research capacities in developing countries.

\section{Copyright (C) 2011 Population Council}

Suggested citation: Jejeebhoy, S. J., A. J. Francis Zavier, R. Acharya and S. Kalyanwala. 2011. Increasing access to safe abortion in rural Maharashtra: Outcomes of a Comprehensive Abortion Care model. New Delhi: Population Council. 



\title{
The Consortium for Safe Abortions in India
}

\author{
Consortium partners: \\ Ipas (Coordinating Partner) \\ Action Research and Training for Health (ARTH) \\ Centre for Enquiry into Health and Allied Themes (CEHAT) \\ Family Planning Association of India (FPAI) \\ Federation of Obstetric and Gynaecological Societies of India (FOGSI) \\ International Maternal and Child Health (IMCH)-Uppsala University \\ Population Council \\ Society of Midwives, India (SOMI) \\ The Consortium was supported by: \\ The Swedish International Development Cooperation Agency (Sida) \\ The David and Lucile Packard Foundation
}





\section{Contents}

List of tables

\begin{tabular}{lc} 
Acknowledgements & ix \\
\hline
\end{tabular}

Chapter 1: Introduction $\quad 1$

Context 1

$\begin{array}{ll}\text { Study objectives } & 1\end{array}$

Background $\quad 2$

Setting $\quad 4$

Study design and samples $\quad 5$

$\begin{array}{ll}\text { Instruments } & 7\end{array}$

$\begin{array}{ll}\text { Analysis } & 8\end{array}$

$\begin{array}{ll}\text { Response rates } & 8\end{array}$

Structure of this report $\quad 9$

Chapter 2: Characteristics of health facilities and social and demographic profiles of households and respondents 10

$\begin{array}{ll}\text { Health facilities } & 10\end{array}$

Community survey 16

Characteristics of households 16

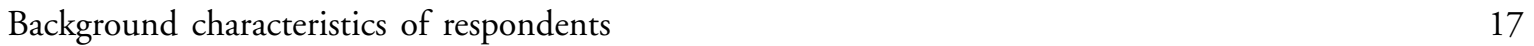

Awareness and perceptions of respondents about abortion, facilities and providers 18

$\begin{array}{ll}\text { Prevalence and experiences of abortion } & 20\end{array}$

Chapter 3: The Comprehensive Abortion Care model 23

$\begin{array}{ll}\text { Objectives } & 23\end{array}$

Setting 23

Implementation $\quad 24$

Facility-based intervention $\quad 24$

Community-based intervention 25

$\begin{array}{ll}\text { Challenges } & 27\end{array}$

Chapter 4: Intervention effects on the health system 28

$\begin{array}{ll}\text { Availability of abortion services } & 28\end{array}$ 
Provider awareness and perceptions $\quad 32$

Availability of IEC materials

Infrastructure and equipment $\quad 35$

Facility and examination room infrastructure $\quad 35$

Essential equipment for the provision of abortion services

Abortion-related service delivery 39

$\begin{array}{ll}\text { Summary } & 45\end{array}$

Chapter 5: Intervention effects on abortion-related awareness among women $\quad 47$

$\begin{array}{ll}\text { Abortion-related information: Sources and messages } & 47\end{array}$

Awareness of abortion methods $\quad 49$

Awareness of facilities providing abortion services $\quad 51$

Perceptions about community access to abortion $\quad 52$

Awareness of legal issues related to abortion $\quad 54$

Summary $\quad 56$

Chapter 6: Experiences of women who underwent abortion 58

Prevalence of abortion: Lifetime and recent $\quad 58$

Abortion-related experiences $\quad 58$

Experiences of second trimester and repeat abortions

Summary

Chapter 7: Summary and conclusions 63

$\begin{array}{ll}\text { Summary } & 63\end{array}$

Facility-level effects $\quad 64$

$\begin{array}{ll}\text { Community-level effects } & 65\end{array}$

$\begin{array}{ll}\text { Limitations } & 66\end{array}$

$\begin{array}{ll}\text { Recommendations } & 67\end{array}$

$\begin{array}{ll}\text { Targeting the most-at-risk } & 67\end{array}$

$\begin{array}{ll}\text { Shifting preferences for services to the public sector } & 67\end{array}$

Extending interventions to the private sector $\quad 68$

$\begin{array}{ll}\text { Addressing post-abortion contraception concerns } & 68\end{array}$

Addressing the quality of abortion care $\quad 68$

Integration of facility- and community-based components 68

$\begin{array}{ll}\text { References } & 69\end{array}$ 


\section{List of tables}

Table 1.1 Socio-demographic characteristics of study districts, 2000s

Table 1.2 Coverage of the study

Table 2.1 Reproductive and child health services provided by PHCs and RHs, Aurangabad and Jalna districts, Maharashtra

Table 2.2 Abortion services provided by PHCs and RHs, Aurangabad and Jalna districts, Maharashtra

Table 2.3 Provider availability at PHCs and RHs, Aurangabad and Jalna districts, Maharashtra

Table 2.4

Provider awareness of grounds for abortion under the MTP Act and perceptions about women's abortion-related rights, Aurangabad and Jalna districts, Maharashtra

Table 2.5 Availability of basic infrastructure at PHCs and RHs in Aurangabad and Jalna districts, Maharashtra

Table 2.6 Availability of basic equipment at PHCs and RHs, Aurangabad and Jalna districts, Maharashtra

Table 2.7 Reproductive and child health related IEC materials displayed at PHCs and RHs, Aurangabad and Jalna districts, Maharashtra

Table 2.8 Characteristics of households, Aurangabad and Jalna districts, Maharashtra

Table 2.9

Socio-demographic profile of respondents, Aurangabad and Jalna districts, Maharashtra

Table 2.10 Awareness and perceptions of respondents about abortion, facilities and providers, Aurangabad and Jalna districts, Maharashtra

Table $2.11 \quad$ Prevalence and experiences of women who had experienced abortion, Aurangabad and Jalna districts, Maharashtra

Table 3.1 Distribution of PHCs and RHs under study, Aurangabad and Jalna districts, Maharashtra

Table 4.1 Constellation of services provided at PHCs and RHs, Aurangabad and Jalna districts, Maharashtra

Table 4.2 Availability of trained abortion providers at PHCs and RHs, Aurangabad and Jalna districts, Maharashtra

Table 4.3 Awareness among PHC- and RH-level medical officers about MTP and their perceptions about abortion and women's abortion-related rights,

Aurangabad and Jalna districts, Maharashtra

Table 4.4 Availability of IEC materials in PHCs and RHs, Aurangabad and Jalna districts, Maharashtra 
Table 4.5 Availability of basic infrastructure at PHCs and RHs, Aurangabad and Jalna districts, Maharashtra

Table 4.6 Examination room infrastructure at PHCs and RHs, Aurangabad and Jalna districts, Maharashtra

Table 4.7 Availability of functioning essential equipment for the provision of abortion services at PHCs and RHs, Aurangabad and Jalna districts, Maharashtra

Table 4.8 PHCs and RHs providing abortion, Aurangabad and Jalna districts, Maharashtra

Table 5.1 Effects of the intervention on information received by women on abortion, Aurangabad and Jalna districts, Maharashtra

Table 5.2 Messages received by women who reported receiving information on abortion in the year preceding the endline interview by source of message, Aurangabad and Jalna districts, Maharashtra

Table 5.3 Effects of the intervention on women's awareness of abortion methods, Aurangabad and Jalna districts, Maharashtra

Table 5.4 Effects of the intervention on women's awareness of facilities providing abortion, Aurangabad and Jalna districts, Maharashtra

Table 5.5 Effects of the intervention on women's perceptions about community access to abortion, Aurangabad and Jalna districts, Maharashtra

Table 5.6 Percentage of women by misperceptions held about the legality of abortion and awareness of at least one situation in which abortion is legal, Aurangabad and Jalna districts, Maharashtra

Table 5.7 Effects of the intervention on women's awareness of the legality of abortion: Summary of logistic regression results using the DiD model, Aurangabad and Jalna districts, Maharashtra

Table 6.1 Prevalence of abortion in the three years preceding the interview, Aurangabad and Jalna districts, Maharashtra

Table 6.2 Percentage of women by facility/individual who conducted the abortion and abortion method used, among women who underwent abortion in the three years preceding the interview, Aurangabad and Jalna districts, Maharashtra

Table 6.3 Percentage of women reporting multiple and second trimester abortions, among women who underwent abortion in the three years preceding the interview, Aurangabad and Jalna districts, Maharashtra

Table 6.4 Percentage of women who received post-abortion contraception counselling, who adopted post-abortion contraception, and for whom the husband's consent was not required, among women who underwent abortion in the three years preceding the interview, Aurangabad and Jalna districts, Maharashtra 


\section{Acknowledgements}

This assessment of a Comprehensive Abortion Care model was conducted by the Population Council on behalf of the Consortium for Safe Abortions in India, comprising Ipas (Coordinating Partner), Action Research and Training for Health (ARTH), the Centre for Enquiry into Health and Allied Themes (CEHAT), the Family Planning Association of India (FPAI), the Federation of Obstetric and Gynaecological Societies of

India (FOGSI), International Maternal and Child Health (IMCH)-Uppsala University, the Population Council and the Society of Midwives, India (SOMI).

Members of the Consortium have played a key role in the design of the assessment, and have given key inputs at various stages of implementation, analysis and interpretation of findings. This was a cooperative endeavour and their inputs are gratefully acknowledged. We would like to express our appreciation, in particular, to Kalpana Apte, Sangeeta Batra, Koyeli Bhattacharjee, Manju Chugani, Padma Deosthali, Sharad Iyengar, Vinoj Manning, Garima Mathias, M. Prakasamma and Jaydeep Tank.

The Consortium for Safe Abortions in India was generously supported by the Swedish International Development Cooperation Agency (Sida) and the David and Lucile Packard Foundation. Additional support from the Packard Foundation enabled the Consortium to undertake the endline survey. We are grateful to these organisations, and, in particular to Yasmin Zaveri-Roy and Lester Coutinho for their support and insights throughout.

The Public Health Department, Government of Maharashtra, the Directorate of Health Services, Mumbai, the State IEC Bureau, Pune, and the State Family Welfare Bureau, Pune, and their regional and district authorities, extended valuable support to both the intervention and its assessment. The core committee, established by the project and chaired by the Deputy Director Health Services, Aurangabad, regularly monitored the progress of project implementation. We are extremely grateful to these public health system staff members for their partnership at all stages of the project.

An earlier draft of this report was extensively and insightfully reviewed by three luminaries in the field of reproductive health: Kurus Coyaji, Iqbal Shah and Leela Visaria. Their thoughtful and provocative comments are much appreciated and have been incorporated into and, thereby, strengthened this report.

We would also like to acknowledge the cooperation of our Ipas partners, and in particular, Vinoj Manning and Sushanto Banerjee whose openness and insights helped us both better understand the intervention and better interpret study findings. Jyoti Moodbidri did an excellent job of editing the report, 
and our report has benefitted greatly from her many suggestions and her careful attention to detail. We would also like to acknowledge with thanks the huge contributions of Komal Saxena, who managed the publication of this report and of MA Jose, who has ably managed the administrative aspects of this study over the last four years. Thanks are due to our team of investigators for their painstaking efforts in collecting data on a topic as sensitive as abortion. Finally, we would like to thank all the women who participated in the study and shared their experiences and insights so willingly. We hope that this report will contribute in some small way to enhancing access to safe abortion services, especially among poor women. 


\section{CHAPTER 1}

\section{Introduction}

\section{Context}

For more than thirty years, following the enactment of the Medical Termination of Pregnancy (MTP) Act of 1971, women in India have been entitled to legal abortion services in registered facilities and by certified providers (Government of India, 1971). Women have the right to access abortions across a range of situations: when the mother's life is at risk or when her physical or mental health is compromised; in case of rape; if the pregnancy is likely to result in the birth of a child with physical or mental abnormalities; and if the pregnancy is the result of contraceptive failure. Besides, abortions may be performed up to 20 weeks of gestation and the consent of the husband or guardian is not required for adult women (aged 18 and above). With these liberal conditions, the MTP Act was intended to reduce the incidence of illegal and unsafe abortions. However, most women continue to obtain abortion services outside of registered settings, and/or from uncertified and often unqualified providers. It is estimated that most of the estimated 6.7 million abortions that are performed in India each year are illegal (Chhabra and Nuna, 1994). Moreover, abortions performed by uncertified providers are estimated to be two to 10 times higher than those performed legally by physicians (Ganatra, 2000), and hold potentially serious adverse consequences for women's health. Indeed, complications arising from abortion contribute to some 8 percent of maternal deaths each year (Office of the Registrar General, India, 2006).
Women's access to safe abortion services from public sector facilities is limited by a range of health system and community-level factors. At the level of the health system, abortion services are rarely available at the Primary Health Centre (PHC) level or in rural areas; most PHCs and even some Community Health Centres (CHCs) lack trained staff and the required equipment and supplies for providing safe abortions (Barge et al., 1998; 2004; Duggal and Barge, 2004; Kalyanwala, Zavier and Jejeebhoy, 2010), or do not have the necessary certification. At the community level, a number of individual- and community-level factors inhibit women from seeking abortion in public sector facilities (see, for example, Elul et al., 2004; Ganatra et al., 2008; Malhotra et al., 2003). These include limited understanding of the legality of abortion, reluctance to obtain services from clinics known to provide abortion services, lack of awareness about the need to seek abortion early in pregnancy, poor perceived quality of care, lack of confidentiality and the frequent insistence on concurrent family planning (Barua and Apte, 2007; Elul et al., 2004; Ganatra, 2000). Indeed, significant numbers of women were reported to have used a home remedy or obtained services from an informal provider in an attempt to terminate their pregnancy; most of these were unsuccessful, leading women to seek services eventually_often in the second trimester-from the formal sector (Elul et al., 2004). 


\section{Study objectives}

Recognising the urgent need to enable rural women to acquire accessible and high quality abortion services, a number of organisations-Ipas (Coordinating Partner), Action Research and Training for Health (ARTH), the Centre for Enquiry into Health and Allied Themes (CEHAT), the Family Planning Association of India (FPAI), the Federation of Obstetric and Gynaecological Societies of India (FOGSI), International Maternal and Child Health (IMCH)-Uppsala University, the Population Council and the Society of Midwives, India (SOMI) — came together in 2006 to form the Consortium for Safe Abortions in India. The goal of the Consortium is to increase access to legal, safe and comprehensive abortion services, including post-abortion family planning, in the public health system, and especially among the rural poor.

One of its key activities was to develop a comprehensive and evidence-based abortion care model suitable for rural women in different settings. The model, which aimed at addressing both facilitybased and community-based barriers, focused on enabling public sector sites to offer comprehensive abortion care services and simultaneously, to build awareness at woman- and community-levels about the legality of abortion and the availability of safe abortion services in the public sector. A more longterm objective was to enhance use of public sector abortion facilities and empower poor rural women to access safe abortion services and services that respond to their need for confidential and nonjudgemental care. This Comprehensive Abortion Care (CAC) model was implemented in one district of a more developed state-Aurangabad district, in Maharashtra-and one district of a lesser developed state, namely Tonk district, in Rajasthan.

This report describes the CAC model implemented in Aurangabad district, Maharashtra, and examines the extent to which the model did indeed improve (a) the availability and quality of abortion services in public sector facilities, notably PHCs and Rural Hospitals (RHs, known as CHCs in other states); and (b) women's awareness and experiences with regard to abortion services. Specifically, the report assesses the extent to which exposure to the intervention resulted in improving infrastructure (including equipment and supplies) and provider skills (including training, knowledge and understanding of abortion), and women's awareness of and perceptions about abortion. It also sheds light on progress in the achievement of such longer term objectives as a shift to public sector facilities and trained providers, and a reduction in second trimester abortions.

\section{Background}

Efforts at collecting primary data on abortion in India have been largely restricted to women who have sought abortion in clinical settings. There are, in contrast, few population-based studies that focus on abortion. The National Family Health Survey (NFHS-2) (IIPS and ORC Macro, 2000) did ask questions on abortion and the questions focused only on inter-birth intervals. Findings suggest considerable under-reporting: just $2 \%$ reported an abortion over the course of their married life (IIPS and ORC Macro, 2000). However, three notable 
studies conducted over the last decade, using more detailed probing, have shed light on the prevalence of abortion and the experiences of women who underwent abortion (Elul et al., 2004; Ganatra et al., 2008; Malhotra et al., 2003). Findings indicate considerable variation in the proportions of women who had ever experienced an abortion: for example, 13\% of women aged 15-44 in Alwar district, Rajasthan, had experienced one or more abortions over the course of their life (Elul et al., 2004) compared to almost one-fourth of those aged 15-39 in six districts of Madhya Pradesh (Malhotra et al., 2003). The case finding approach used in the Maharashtra study among women in three western districts estimated, moreover, an annual induced abortion rate of 15\% (Ganatra et al., 2008). Abortion ratios - the number of abortions per 100 live births-also varied, ranging from about five for every 100 live births in Madhya Pradesh and Rajasthan to more than twice that (11-14, depending on the methodology employed) in Maharashtra.

These studies also document women's knowledge of the legality of abortion, awareness and practice of sex-selective abortion, providers from whom women sought their abortion, and the post-abortion complications they experienced. They confirm that while knowledge of the legality of abortion was limited, most women were aware of sex-selective abortion. For example, three-quarters of women in the Rajasthan study knew that foetal sex could be determined and a similar proportion knew someone who had undergone a sex-selective abortion. Moreover, 3\% of women who underwent abortion in the Rajasthan and Madhya Pradesh studies compared to $17 \%$ of those in the Maharashtra study, reported sex-selection as a reason for their abortion.

Variation was also observed in the percentage of women who obtained services from outside the formal sector. For example, $20 \%$ of the women who had sought an abortion in the five years preceding the interview in the Rajasthan study reportedly used a home remedy or the services of an informal provider (Elul et al., 2004) while half of rural women in the Madhya Pradesh study, reported an abortion using "dubious and potentially dangerous means" (Malhotra et al., 2003). In Maharashtra, $45 \%$ of all abortions were carried out by providers who were either not legally recognised as MTP service providers or performed in a place not legally approved for abortion; most were conducted by allopathic physicians not certified to provide abortion, and just $2 \%$ and $12 \%$ were conducted by traditional practitioners and those trained in nonallopathic systems of medicine, respectively.

Post-abortion morbidity was reported by large proportions of women: $68 \%$ in the Maharashtra study, 54\% in the Madhya Pradesh study and 26\% in the Rajasthan study.

In general, in India, few public sector health facilities provide abortion services, and leading obstacles that prevent women's access to these services include a lack of trained providers, appropriate infrastructure or necessary equipment and supplies (Barge et al., 1998; 2004; Duggal and Barge, 2004; Kalyanwala, Zavier and Jejeebhoy, 2010). Many of those that provide abortion services, moreover, continue to use Dilation and Curettage (D\&C) for first trimester abortions (Barge et al., 
2004), a method internationally recognised as inappropriate in general, and only to be used when Manual Vacuum Aspiration (MVA) or medical methods of abortion are unavailable (World Health Organization, 2003).

There have been concerted efforts by the Government of India to increase access to safe abortion services at the PHCs. As early as 2000, the National Population Policy (NPP) (Ministry of Health and Family Welfare, 2000) noted the provision of safe abortion services as an important strategy for reducing maternal deaths. Recognising the need to increase access to safe abortion, particularly in rural areas, the Policy recommended expanding abortion services to the PHC level. Notably, in an attempt to expand the provider base for services in general, the National Rural Health Mission, 2005, added a new cadre of service providers, including doctors trained in the Ayurveda and Homoeopathy branches of medicine (Ministry of Health and Family Welfare, 2005). Also notably, the rules and regulations governing the MTP Act were amended in May 2003 to specify that Medical Abortion (MA) could be provided by certified providers in unregistered facilities, as long as they had access to a registered facility for back-up (Government of India, 2003); as a result, medical abortion can now be provided at the PHC level, provided that back-up surgical support at a higher facility is readily available for referral. Furthermore, the Ministry of Health and Family Welfare has specific strategies to increase access to safe abortion services both at the community and facility levels. At the community level, strategies include spreading awareness on issues related to safe abortion services.
At the provider level, training of Auxiliary Nurse Midwives (ANMs) and Accredited Social Health Activists (ASHAs) to provide confidential counselling is advocated; ANMs, ASHAs and Anganwadi Workers (AWWs) are expected to counsel and refer women as well as provide post-abortion care. At the facility level, the aim is to ensure the availability of quality MVA technologies at all CHCs and First Referral Units (FRUs), and at least half of all 24/7 PHCs, and to encourage the provision of quality MTP services by the private and NGO sectors (Ministry of Health and Family Welfare, 2010). Guidelines to provide MVA up to eight weeks of gestation at the PHC level have also been prepared, thus further paving the way for increased access to safe abortion services nationwide (Ministry of Health and Family Welfare, 2001).

\section{Setting}

Aurangabad district was selected purposively as the intervention district for implementing the CAC model because of the previous engagement of Ipas, the Consortium's implementation partner, in this district. Nevertheless, the district was not atypical of Maharashtra in terms of socio-demographic characteristics as shown in Table 1.1. The control district, Jalna, was matched on the basis of literacy and economic activity profiles. As evident from Table 1.1, by and large, the socio-demographic characteristics of the intervention and control districts are similar.

In Maharashtra, Aurangabad accounted for about $3 \%$ and Jalna $2 \%$ of the state's total population of 96.8 million as of 2001 (Office of 


\section{Table 1.1}

Socio-demographic characteristics of study districts, 2000s

\begin{tabular}{|c|c|c|c|}
\hline & \multicolumn{3}{|c|}{ Maharashtra } \\
\hline & Aurangabad & Jalna & Maharashtra \\
\hline Total population $^{1}$ & $2,897,013$ & $1,612,980$ & $96,878,627$ \\
\hline Sex ratio $(M / F)^{1}$ & 924 & 951 & 922 \\
\hline Juvenile sex ratio $(M / F)^{1}$ & 890 & 903 & 913 \\
\hline Male literacy $(\%)^{1,2}$ & 84.9 & 79.1 & 86.0 \\
\hline Female literacy $(\%)^{1,2}$ & 60.1 & 49.0 & 67.0 \\
\hline Male work participation $(\%)^{1,2}$ & 59.1 & 60.2 & 62.1 \\
\hline Female work participation $(\%)^{1,2}$ & 37.0 & 45.6 & 35.8 \\
\hline Urban $(\%)^{1}$ & 38.8 & 19.1 & 42.4 \\
\hline Modern contraceptive use $(\%)^{3}$ & 55.5 & 54.3 & 60.8 \\
\hline Unmet need for contraception $(\%)^{3}$ & 14.4 & 12.8 & 12.6 \\
\hline $\begin{array}{l}\text { Mothers who had at least three antenatal check-ups for the } \\
\text { last birth }(\%)^{3}\end{array}$ & 28.0 & 13.2 & 23.0 \\
\hline Institutional deliveries $(\%)^{3}$ & 54.8 & 51.3 & 57.9 \\
\hline Skilled attendance at delivery $(\%)^{3}$ & 60.5 & 56.0 & 62.6 \\
\hline
\end{tabular}

${ }^{1}$ Office of the Registrar General and Census Commissioner (2004).

${ }^{2}$ Ages 7 and above.

${ }^{3}$ International Institute for Population Sciences (2006).

the Registrar General and Census Commissioner, 2004). Gender differences are quite stark in both districts-for example, literacy rates in Aurangabad ranged from $60 \%$ among females to $85 \%$ among males; in Jalna, correspondingly, they ranged from $49 \%$ among females to $79 \%$ among males. Urban populations and the percentage of women who reported full ANC care differed widely between districts, however both districts were similar in terms of work participation levels, modern contraceptive use, institutional deliveries and deliveries by skilled birth attendants.

The intervention (described in detail in Chapter 3) was implemented in Aurangabad district in general. However, on the basis of the availability of basic infrastructure and the array of services provided, as recorded in the baseline assessment, 23 of the 50 PHCs in the district were selected for special attention, along with all the RHs (for more details, see Kalyanwala, Zavier and Jejeebhoy, 2010) and community awareness-building activities were conducted in the areas served by these selected PHCs.

\section{Study design and samples}

A quasi-experimental research design, with crosssectional surveys undertaken in control and intervention districts prior to the implementation of the CAC model intervention (baseline) and at its conclusion (endline), was used to evaluate the effects 
of intervention activities. The baseline investigation was conducted during August-November 2007; the endline during February-May 2010. Two surveys were conducted: at health facility and at community levels among married women aged 15-39-those most likely to have experienced a recent pregnancyat both base- and end-line.

Facility surveys were conducted in all RHs and PHCs of Aurangabad and Jalna. During the facilitybased survey phase, we thus covered all of the 106 facilities in the two districts at baseline (50 PHCs and nine RHs in Aurangabad, and 37 PHCs and 10 RHs in Jalna), and all of the 108 facilities in the two districts at endline (45 PHCs and $14 \mathrm{RHs}$ in Aurangabad, and 39 PHCs and 10 RHs in Jalna).

Sites for the community-based survey were selected purposively from among the PHC areas selected for intervention in Aurangabad, and a correspondingly identified set of $18 \mathrm{PHCs}$ areas in the control site, Jalna. At the time of the endline survey, in-depth interviews were also conducted with women who had undergone abortion in the ten years prior to the interview in order to probe their experiences in greater detail than in the baseline survey.

Within each selected PHC area, communitybased surveys of currently married women aged 15-39 were conducted in a sample of villages served by the facilities selected for intervention in Aurangabad and a similarly situated set of villages in Jalna, at both baseline and endline. The required sample size was determined as 1,000 per district for the baseline survey, based on a presumed lifetime incidence of abortion of $10 \%$, drawing from previous studies (for details of the selection procedures, see Jejeebhoy, Zavier and Kalyanwala, 2010). We reduced the required sample size for the endline survey to 850 per district, based on the actual lifetime incidence of abortion obtained from the baseline survey $(12.8 \%)$, which was higher than the rate adopted for the baseline survey. Correspondingly, a total of 40 and 28 Primary Sample Units (PSUs) or villages were selected for interview from each district at the time of the baseline and endline surveys, respectively, and an average of 33 and 36 women, respectively, were interviewed from each selected PSU. PSUs and respondents within each PSU were drawn independently at the two points in time; the probability that any woman was included in both baseline and endline surveys is remote.

The 2001 Census list of villages served as the sampling frame for the selection of villages. At the first level of stratification, each district was stratified into blocks and the number of villages to be selected from each block was determined according to the share of the population of that block to that of the district. In each block, villages were further stratified by size and the percentage of the populations belonging to scheduled castes or scheduled tribes. The last level of stratification consisted of an order of villages within each stratum by level of female literacy, ordered alternatively in increasing and decreasing levels of female literacy (obtained from the 2001 Census Primary Census Abstract). Villages were then selected systematically from this stratified list, with selection probability proportional to size (PPS). 
A complete mapping and household listing operation was carried out in each selected PSU or in selected segments or linked villages as appropriate (large villages were segmented into approximately 150 households and two segments were selected randomly). The list of households provided the necessary frame for selecting households at the second stage. In each PSU, the households to be interviewed were selected by systematic sampling. The sampling design was intended to ensure a selfweighting design at the district level. All eligible women in the selected household were selected for interview and no replacement was permitted.

\section{Instruments}

The facility study instrument comprised three components: questions relating to the facility itself, its staffing pattern, types of services provided with a particular focus on abortion-related services and training, and quality of facilities; a facility-level checklist that assessed health centre infrastructure and availability of essential equipment and supplies; and a component on provider awareness about abortion-related issues.

The community-based survey instruments drew on those used in previous studies, notably those by Elul et al. (2004) and Malhotra et al. (2003) discussed above. Two structured instruments - a household questionnaire and a woman's questionnaire-were used to collect data in a face-to-face interview. The household questionnaire was designed to gather demographic information about all permanent household members, as well as information on household socio-economic status. It was also used to identify currently married women aged 15-39 who would be eligible for the individual interview.

The woman's questionnaire included background information of female respondents as well as their reproductive and abortion experiences, knowledge of abortion legislation and available methods of abortion, and key issues in selecting an abortion provider or facility. Abortion experiences covered the method of abortion experienced (surgical, medical), complications experienced and quality of care received. Information on women's reproductive experiences was obtained using (a) a detailed birth history, and (b) a detailed history of reproductive events experienced in the five years prior to the interview by way of a calendar that provided month-wise data on women's pregnancy status, contraceptive practice, abortions, stillbirths and miscarriages. At the time of the endline survey, an identical set of questions was posed, with additional questions relating specifically to the intervention in order to gauge women's direct exposure to the intervention. Besides, 25 women from Aurangabad who had experienced an abortion in the ten years preceding the interview were interviewed in-depth about their experience, including with regard to access to abortion services, quality of care and post-abortion contraception (not presented in this report).

Study instruments were prepared in English and translated into Marathi. They were pre-tested and modified accordingly.

At the time of the baseline survey, interviews were conducted using paper questionnaires; survey 
data were entered in CSPro 4.0. At the time of the endline survey, interviewers recorded women's responses directly on to mini laptop computers, using a data entry package prepared using CSPro, thus ensuring built-in consistency checks and rapid transmission of data from the field to the Council office. All data were analysed using SPSS-11.0. Findings of the facility-based survey are presented by way of means and percentages (PHCs) and absolute numbers (RHs). Findings of the community-based survey are reported by way of means, medians, percentages and odds ratios.

\section{Analysis}

Descriptive data are presented that compare changes observed over time in Aurangabad, the intervention site, and Jalna, the control site, in terms of facility preparedness to provide abortion, women's awareness of abortion-related matters, and the experiences of women who underwent abortion in the three years prior to the baseline and endline investigations. The significance of changes in each district over the period between the baseline and endline surveys was tested using t-tests. In addition, in order to assess the effect of the intervention on women's abortion-related awareness, logistic regression techniques using Difference-in-Difference (DiD) models were employed. The DiD method (Ashenfelter, 1978; Ashenfelter and Card, 1985) is a statistical method that contrasts the difference in average outcome in the intervention group before and after exposure to the intervention, with the difference in average outcome in the control group at baseline and endline, after controlling for a host of socio-demographic factors. Thus, the DiD method enables us to compare changes that have taken place in the intervention site following programme implementation with those that have occurred in the control site during the same period.

\section{Response rates}

Table 1.2 provides the response rates for household and individual interviews. In the baseline survey, a total of 3,379 households (1,634 and 1,745 in Aurangabad and Jalna, respectively), yielding a total of 2,956 eligible women (1,456 and 1,500 in the two districts, respectively) were approached to participate in the study. Similarly, at the endline,

\section{Table 1.2}

\section{Coverage of the study}

\begin{tabular}{|c|c|c|c|c|}
\hline & \multicolumn{2}{|c|}{ Baseline } & \multicolumn{2}{|c|}{ Endline } \\
\hline & Aurangabad & Jalna & Aurangabad & Jalna \\
\hline Number of villages selected & 40 & 40 & 28 & 28 \\
\hline Number of households selected & 1,634 & 1,745 & 1,399 & 1,570 \\
\hline Household response rate & 95.5 & 97.0 & 95.4 & 93.8 \\
\hline $\begin{array}{l}\text { Number of currently married women } \\
\text { aged } 15-39 \text { identified }\end{array}$ & 1,456 & 1,500 & 1,151 & 1,188 \\
\hline Response rate for eligible women & 89.8 & 89.3 & 88.0 & 85.6 \\
\hline
\end{tabular}


2,969 households $(1,399$ and 1,570 in the two districts, respectively) and a total of 2,339 eligible women (1,151 and 1,188 in the two districts, respectively) were so approached. Household response rates at the time of the baseline and endline surveys ranged from $94-97 \%$; corresponding response rates for eligible women ranged from $86-90 \%$.

\section{Structure of this report}

The report contains seven chapters. Chapter 2, drawing on data from the baseline surveys, describes the facility situation as well as the profile of women interviewed in the community-based survey, including their socio-demographic characteristics, their awareness and perceptions of abortion, the prevalence of abortion and experiences of those who had undergone abortion in the two districts.
Chapter 3 briefly describes the Comprehensive Abortion Care model implemented in Aurangabad and the key components of the intervention, including women's exposure to abortion-related messages. Chapter 4 examines the extent to which the intervention resulted in improved availability of services and the readiness of facilities to provide abortion in Aurangabad as compared with Jalna. Chapter 5 assesses the effect of the intervention on women's awareness of abortionrelated matters, and Chapter 6 describes the prevalence of abortion at the time of baseline and endline interviews, and the experiences of women who underwent abortion in the three years preceding the interview. Chapter 7 summarises the findings of this study and offers programmatic recommendations to ensure greater access to safe abortion among rural women in the state. 


\section{Characteristics of health facilities and social and demographic profiles of households and respondents}

In this chapter, we draw on data from the baseline investigation and set the context in which intervention activities were implemented. It presents an overview of the basic infrastructure, constellation of services provided and availability of abortion services. It also discusses the socio-demographic profiles of study households and individual respondents, the awareness and perceptions of respondents regarding abortion, abortion prevalence, and the experiences of women who had undergone abortion. Findings of the community-based surveyall means, medians and percentages - have been weighted using normalised weights for the total population. However, in order to show the total number of women interviewed, unweighted numbers of respondents (Ns) are provided in each table. Because numbers are unweighted and percentages are weighted, we caution readers against deriving numbers based on the percentages provided in the tables.

\section{Health facilities}

In total, in the two districts, there were 87 PHCs and 19 RHs: 50 and 37 PHCs, and nine and 10 RHs in Aurangabad and Jalna, respectively, at the time of the baseline survey. As Table 2.1 shows, while all the facilities provided a range of reproductive health services, abortion services were rarely provided. For example, all the PHCs and RHs provided antenatal, postpartum and contraceptive services; and all the RHs and four-fifths and twothirds of PHCs, respectively, provided delivery services and conducted tubal ligation. In contrast, abortion services were rarely provided: just one (1\%) of the 87 PHCs and five of the 19 RHs were providing abortion at the time of the baseline interview. In addition, eight (9\%) PHCs and five $\mathrm{RH}$ s reported that abortion services were provided in the past but had been discontinued.

Among facilities providing abortion services at the time of the interview (Table 2.2), moreover, most conducted relatively few procedures; indeed, just one of the five RHs providing abortion had conducted 100 or more abortions in the 12 months preceding the interview and three more had conducted between 51 and 99 abortions. Just three of the five RHs provided second trimester abortions. Notably, four of the five RHs reported that abortions were provided three or more days a week or on demand, and all, including the single PHC providing abortion services, provided postabortion contraception. Legal provisions of the MTP Act were not always observed. While all the RHs maintained an MTP register, just three had written guidelines available at the facility. Almost all the facilities continued to require the husband's written consent and many refused abortion to minors and the unmarried. 


\section{Table 2.1}

Reproductive and child health services provided by PHCs and RHs, Aurangabad and Jalna districts, Maharashtra

\begin{tabular}{|c|c|c|}
\hline & PHCs (\%) & RHs (n) \\
\hline Number of facilities & 87 & 19 \\
\hline ANC and postpartum services & 100.0 & 19 \\
\hline Delivery services & 80.5 & 19 \\
\hline Provision of contraception & 100.0 & 19 \\
\hline Non-terminal methods (condom, oral contraceptive, IUD) & 100.0 & 19 \\
\hline Tubal ligation & 65.5 & 19 \\
\hline Vasectomy & 40.2 & 13 \\
\hline Abortion services currently available ${ }^{1}$ & 1.1 & 5 \\
\hline Abortion services not currently available ${ }^{1}$, but provided earlier & 9.2 & 5 \\
\hline
\end{tabular}

${ }^{1}$ Provided in the three months preceding the interview.

\section{Table 2.2}

Abortion services provided by PHCs and RHs, Aurangabad and Jalna districts, Maharashtra

\begin{tabular}{|c|c|c|}
\hline Facilities currently providing abortion services & PHCs (n) & RHs (n) \\
\hline Number of facilities & 1 & 5 \\
\hline Number of abortions conducted (12 months preceding $t$ & & \\
\hline 50 or less & 1 & 1 \\
\hline $51-99$ & 0 & 3 \\
\hline 100 or more & 0 & 1 \\
\hline Provide second trimester abortion & 0 & 3 \\
\hline Provide abortion services $>2$ days a week or on demand & 1 & 4 \\
\hline Provide post-abortion contraception & 1 & 5 \\
\hline Written guidelines available at facility & 0 & 3 \\
\hline Maintain MTP register & 0 & 5 \\
\hline Abortion provided to minors & 0 & 2 \\
\hline Abortion provided to the unmarried & 0 & 3 \\
\hline Husband's signature mandatory & 1 & 4 \\
\hline
\end{tabular}

${ }^{1}$ Estimated for one PHC and 2 RHs; obtained from registers in $3 \mathrm{RHs}$. 
Table 2.3 presents data on the availability of trained doctors and the sex composition of medical officers and highlights that staffing patterns may indeed pose a major obstacle to women's access to safe abortion services. Findings suggest that while every facility had at least one medical officer, just $10 \%$ of all PHCs and 14 of the 19 RHs had at least one medical officer who was certified to provide MTP services. In addition, many facilities were staffed by male doctors only-an enormous socio-cultural barrier inhibiting the acceptability of abortion at public health facilities: just $29 \%$ of the PHCs had at least one female doctor, and even at the RH level, just 11 of the 19 RHs so reported. Nursing staff were more widely available, with an average of seven and 10 nursing staff available per PHC and RH, respectively.
Moreover, not all providers were aware of the new techniques of abortion on the one hand and stipulations of the MTP Act and women's abortionrelated rights on the other (Table 2.4). For example, $87 \%$ of the 78 PHC doctors and 16 of the 19 $\mathrm{RH}$ doctors interviewed were aware that Medical Abortion (MA) is only prescribed for termination of pregnancy up to seven weeks in India; $77 \%$ and 15 , respectively, were aware that only MTP-certified providers are legally permitted to provide medical abortion; and just $50 \%$ and 10 , respectively, were aware that the consent of the husband or guardian is not required for women aged 18 and older. While the majority perceived that women should obtain confidential counselling, just three-quarters of all providers at the PHC level, and half those at the RH level believed it necessary to fully inform women about the specifics of the procedure they were to undergo.

Table 2.3

Provider availability at PHCs and RHs, Aurangabad and Jalna districts, Maharashtra

\begin{tabular}{l|c|c|}
\hline & PHs (n) \\
\hline Number of facilities & $\mathbf{8 7}$ & $\mathbf{1 9}$ \\
Availability of doctors at each facility & & 12 \\
At least one medical officer (PHC), 4 medical officers (RH) ${ }^{1}$ & 100.0 & 4.7 \\
Mean number of doctors & 1.6 & 11 \\
Facilities with at least one female doctor & 28.7 & 14 \\
Facilities with at least one certified MTP provider ${ }^{2}$ & 10.3 & 9 \\
Availability of nursing staff & & 9.9 \\
Facilities with at least 4 (PHC) and 9 (RH) nursing staff ${ }^{3}$ & 92.0 & 7.1
\end{tabular}

${ }^{1}$ The minimum required number of medical officers is one at PHCs and 4 at RHs.

${ }^{2}$ In addition, one doctor posted at a PHC in Aurangabad reported that he had received MTP training but had not been certified at the time of the survey.

${ }^{3}$ The minimum required number of nursing staff is 4 at PHCs and 9 at RHs. 


\section{Table 2.4}

Provider awareness of grounds for abortion under the MTP Act and perceptions about women's abortionrelated rights, Aurangabad and Jalna districts, Maharashtra

\begin{tabular}{|c|c|c|}
\hline & PHCs (\%) & RHs (n) \\
\hline Number of facilities & $78^{1}$ & 19 \\
\hline \multicolumn{3}{|l|}{ Awareness of grounds for legal abortion } \\
\hline MA is only prescribed for early abortion & 87.2 & 16 \\
\hline Only MTP certified MBBS doctors are permitted to prescribe MA & 76.9 & 15 \\
\hline $\begin{array}{l}\text { The opinion of more than one registered doctor is required for } \\
\text { abortions performed at } 12-20 \text { weeks of pregnancy }\end{array}$ & 52.6 & 15 \\
\hline $\begin{array}{l}\text { Consent of husband (or guardian) for abortion is not required for } \\
\text { women aged } 18 \text { and above }\end{array}$ & 50.0 & 10 \\
\hline \multicolumn{3}{|l|}{ Perceptions about women's rights: perceive that women should } \\
\hline Undergo counselling privately & 85.9 & 17 \\
\hline $\begin{array}{l}\text { Be fully informed about the specifics of the medical procedure she is } \\
\text { to undergo }\end{array}$ & 75.6 & 9 \\
\hline
\end{tabular}

${ }^{1}$ Doctors were not available in 9 facilities.

Another fundamental factor inhibiting the readiness of facilities to provide abortion services relates to lack of appropriate infrastructure. Findings, presented in Table 2.5, reiterate that even the basic infrastructure required to provide health care services, in general, remains inadequate. For example, while $92 \%$ of the PHCs contained the four beds considered a minimum requirement for PHCs, $10 \%$ did not have electricity facilities, and just two-thirds had regular access to transport facilities in case of emergency. Although the infrastructure was considerably better at the RH level, just 14 of the 19 RHs contained 30 beds, the minimum requirement for RHs in general, and just 15 of the $19 \mathrm{RHs}$ had regular access to transport facilities in case of emergency. Moreover, just $43 \%$ of all PHCs and 12 of the 19 RHs contained all four facilities (minimum number of beds, electricity, piped water and regular transport facility). Examination room infrastructure was also limited: just $15 \%$ of all PHCs and 14 of the 19 RHs contained a separate examination room, visual privacy, an operating table with stirrups and a wash basin with running water.

Also inhibiting readiness to provide abortion services is the lack or uneven distribution of equipment essential for providing services. As Table 2.6 shows, although abortion-related equipment was not universally available, it was available in considerably more facilities than those providing abortion at the time of interview. For example, among the 19 RHs, while five were providing abortion at the time of interview, 17 contained Electric Vacuum Aspiration (EVA) and/or MVA equipment. Likewise, while just one PHC was providing abortion, as many as $46 \%$ had EVA 


\section{Table 2.5}

Availability of basic infrastructure at PHCs and RHs in Aurangabad and Jalna districts, Maharashtra

\begin{tabular}{|c|c|c|}
\hline & PHCs (\%) & RHs (n) \\
\hline Number of facilities & 87 & 19 \\
\hline \multicolumn{3}{|l|}{ Beds available } \\
\hline Average number of beds & 7.7 & 30.0 \\
\hline At least 4 (PHC) and $30(\mathrm{RH})$ beds available & 92.0 & 14 \\
\hline \multicolumn{3}{|l|}{ Electricity available } \\
\hline Electricity connected & 90.1 & 19 \\
\hline \multicolumn{3}{|l|}{ Water supply } \\
\hline Main source of water supply_-piped water & 52.9 & 14 \\
\hline \multicolumn{3}{|l|}{ Transport } \\
\hline Transport and fuel regularly available for referral & 67.8 & 15 \\
\hline \multicolumn{3}{|l|}{ General infrastructure } \\
\hline $\begin{array}{l}\text { Facilities with electricity, at least } 4 \text { beds (PHC) and } 30 \text { beds (RH), } \\
\text { piped water and regular transport facility }\end{array}$ & 42.5 & 12 \\
\hline \multicolumn{3}{|l|}{ Examination room infrastructure } \\
\hline Separate room for examination & 85.1 & 19 \\
\hline Visual privacy & 81.6 & 19 \\
\hline Wash basin with running water & 18.5 & 15 \\
\hline Operating table (with stirrups) & 64.4 & 18 \\
\hline Facilities with all of the above & 14.9 & 14 \\
\hline
\end{tabular}

Table 2.6

Availability of basic equipment at PHCs and RHs, Aurangabad and Jalna districts, Maharashtra

\begin{tabular}{|c|c|c|}
\hline & PHCs (\%) & RHs (n) \\
\hline Number of facilities & 87 & 19 \\
\hline \multicolumn{3}{|c|}{$\begin{array}{l}\text { Availability of functioning essential equipment for the provision of } \\
\text { abortion services }\end{array}$} \\
\hline MVA or MR syringe & 4.6 & 6 \\
\hline Suction machine (EVA) & 43.7 & 17 \\
\hline EVA or MVA equipment & 46.0 & 17 \\
\hline Tenaculum/Volsellum & 46.0 & 14 \\
\hline Suction cannulae & 13.8 & 11 \\
\hline Set of dilators & 12.6 & 11 \\
\hline \multicolumn{3}{|l|}{ Infection prevention/sterilisation equipment } \\
\hline Autoclave drum & 87.4 & 18 \\
\hline \multicolumn{3}{|l|}{ Facilities with essential equipment } \\
\hline EVA or MVA equipment, volsellum, cannuale and autoclave & 8.0 & 9 \\
\hline
\end{tabular}


or MVA equipment. However, related essential equipment such as suction cannulae and volsellum were available in relatively few facilities. Finally, infection prevention/sterilisation equipment was not available at all facilities, particularly at the PHC level. Indeed, just $8 \%$ of all PHCs and nine of the $19 \mathrm{RHs}$ had all of the essential equipment for the provision of EVA or MVA.

Yet another deterrent to abortion service readiness was the paucity of abortion-related IEC materials in facilities (Table 2.7). Indeed, while four-fifths or more PHCs and RHs reported the availability of IEC materials pertaining to child health, family planning and HIV/AIDS, information on abortion-related issues was relatively less likely to be available. Moreover, what was available focused on the illegality of sex selection and sex-selective abortion in $61 \%$ of the PHCs and 16 of the 19 RHs. In contrast, just $6 \%$ of the PHCs and seven of the 19 RHs reported the availability of materials pertaining to the legality and availability of abortion services, or on dispelling the confusion between restrictions on sex-selective abortion and the right to undergo medical termination of pregnancy.

\section{Table 2.7}

Reproductive and child health related IEC materials displayed at PHCs and RHs, Aurangabad and Jalna districts, Maharashtra

\begin{tabular}{|c|c|c|}
\hline & PHCs (\%) & RHs (n) \\
\hline Number of facilities & 87 & 19 \\
\hline Child health including immunisation & 95.4 & 19 \\
\hline Maternal health & 69.0 & 18 \\
\hline Breastfeeding & 62.1 & 17 \\
\hline Family planning (including posters, brochures, samples) & 79.3 & 19 \\
\hline RTI/STI & 57.5 & 18 \\
\hline HIV/AIDS & 79.3 & 19 \\
\hline Illegality of sex-selection practices and abortion & 60.9 & 16 \\
\hline Legality, availability of abortion & 5.8 & 7 \\
\hline
\end{tabular}




\section{Community survey}

The community-level baseline survey was conducted in a total of 80 villages in the two districts; a total of 3,253 households were reached, and from these households, a total of 2,647 currently married women aged 15-39 were interviewed.

\section{Characteristics of households}

As evident in Table 2.8, the majority of structures in which the respondents resided were self-owned (90\%); the majority of respondents also owned agricultural land (69\%). The average household size was about 5 . Household amenities were, however, limited: just $31 \%$ lived in a pucca structure, just $12 \%$ had their own flush toilet, $71 \%$ had electricity, and for $27 \%$, the main source of drinking water was their own piped water/hand pump/covered well.

Household economic status was measured using an index composed of household asset data on ownership of selected durable goods as well as data on access to amenities, and ownership of agricultural land; it was adapted from the household standard of living index used in the Youth in India: Situation and Needs study (International Institute for Population Sciences and Population Council, 2010). The index was constructed using a host of amenities and scores ranged from 0 to 53 (for details, see Jejeebhoy, Zavier and Kalyanwala, 2010). The mean score on the standard of living index was 15.0, reflecting a relatively low overall economic status.

\section{Table 2.8}

Characteristics of households, Aurangabad and Jalna districts, Maharashtra

\begin{tabular}{|c|c|}
\hline Number of households & Households \\
\hline Ownership of residence, agricultural land & 3,253 \\
$\quad$ Residence (\%) & 90.0 \\
$\quad$ Agricultural land (\%) & 68.6 \\
Household size: Mean number of usual household members & 5.2 \\
Type of house: Pucca structure (\%) & 30.7 \\
Household amenities & 11.7 \\
$\quad$ Toilet facility: own flush toilet (\%) & 70.7 \\
$\quad$ Source of lighting: electricity (\%) & 27.0 \\
$\quad$ Source of drinking water: own piped water/hand pump/covered well (\%) & 15.0 \\
Economic status &
\end{tabular}

Note: All Ns are unweighted. 


\section{Background characteristics of respondents}

Table 2.9 presents the socio-economic characteristics of respondents. On average, respondents were 26 years old, 38\% had never been to school, 16\% had completed at least Class 10, and 57\% had worked in the 12 months preceding the interview. As far as fertility levels are concerned, on average, women reported about 2.3 and 2.1 live births and surviving children, respectively, and 15\% had experienced one or more child deaths. Contraceptive awareness was high; awareness of even non-terminal methods was almost universal and 66\% of respondents had ever practised contraception at some point in their life. At the time of the interview, 56\% were practising contraception, with about three-quarters of these women reporting tubal ligation.

Table 2.9

Socio-demographic profile of respondents, Aurangabad and Jalna districts, Maharashtra

Socio-demographic factors

Number of women

Current age (years): Mean

Educational attainment

Never attended school (\%)

Completed Class 10 or higher (\%)

Mean years of education completed

\section{Working status}

Worked in the last year (\%)

Fertility and child mortality

Mean number of children ever born

Mean number of surviving children

Experienced at least one child death (\%)

\section{Contraception}

Aware of at least one non-terminal method (\%)

Ever practised contraception (\%)

Practising contraception at the time of interview (\%)

Terminal method

Modern non-terminal method

Traditional method
Women aged 15-39

\section{2,647}

25.7

37.9

16.4

4.5

57.4

2.3

2.1

14.8

89.6

66.0

56.4

41.9

11.6

2.9

Note: All Ns are unweighted. 
Awareness and perceptions of respondents about abortion, facilities and providers

In order to capture the extent to which lack of awareness may pose a barrier to safe abortion, the survey explored women's awareness about abortion and its legal status, as well as of facilities in which abortion is provided. Findings, described in Table 2.10, confirm that awareness remains patchy and may well impede women's access to safe abortion.

Women were asked about methods of abortion, and those who reported awareness of surgical or medical methods were probed about their correct awareness of these methods. Findings show that a significant minority of women had no idea about how abortion is performed (17\%). In addition, fewer women were aware of medical than surgical abortion (50\% versus $77 \%$ ); even so, it is likely that not all women who reported awareness of medical abortion were referring to the mifepristone-misoprostol combination, but rather to the numerous traditional preparations available in their village or neighbouring villages.

Knowledge of the legality of abortion was also far from universal. While the majority of women $(77 \%)$ were aware of at least one situation in which abortion is legal in India, an equal proportion (73\%) held one or more misconceptions about women's right to obtain abortion. More specifically, as many as half of all women believed that abortion is not legally available to unmarried women (49\%) or to those who have experienced contraceptive failure (50\%), and 30-34\% believed that abortion is not legally available to women whose health is endangered by the pregnancy or who have a strong chance of foetal malformation. Further, a considerable proportion (88\%) of women believed that it is mandatory for women undergoing abortion to have their husband's consent.

Awareness of the location of abortion facilities and providers was also limited. For example, 27\% of all women were unaware that abortion services were available at public or private sector facilities in their district, and at the same time, an almost equal proportion-one-quarter-reported that abortion services were available from providers currently outside the provisions of the Act. Awareness that abortion is conducted in a public sector facility was also limited: just $38 \%$ of women reported such awareness, compared to $62 \%$ reporting awareness that abortions are conducted in private sector facilities.

Despite their limited awareness of the legality of abortion, most women endorsed women's right to abortion. In response to questions on whether they agreed that women should access abortion in a variety of circumstances, between $75 \%$ and $92 \%$ of the women agreed that women should access abortion if her health is endangered, if she is unmarried, if the pregnancy results from rape, if there is a chance of serious health problems in the infant, and if she does not want or cannot afford a child (not shown in table).

Finally, awareness about foetal sex determination and the prevalence of sex-selective abortion was quite widespread. Over four in five women (85\%) knew that foetal sex can be determined, and among those who knew so, about half believed that sex determination was somewhat 


\section{Table 2.10}

Awareness and perceptions of respondents about abortion, facilities and providers, Aurangabad and Jalna districts, Maharashtra

\section{Number of women \\ Awareness of any method of abortion (\%) \\ Awareness of specific abortion methods (\%) \\ Surgical \\ Medical}

\section{Awareness of legality of abortion}

Women correctly aware of (\%)

At least one condition under which abortion is legal (of 6 conditions)

\section{Misperceptions held (\%)}

At least one misperception about the conditions under which abortion is legal

Illegal for an unmarried woman to access abortion

Illegal for a woman whose pregnancy results from contraceptive failure ("accidentally")

to access abortion

Illegal for a woman whose pregnancy has resulted from rape to access abortion

Illegal for a woman whose health is endangered by the pregnancy to access abortion

Even if there is a strong chance of foetal malformation, illegal for a woman to access abortion

Illegal for a woman who is more than 20 weeks pregnant to access abortion

A woman undergoing abortion requires her husband's (or guardian's) consent

Awareness of abortion facilities and providers (\%)

Aware of public or private sector facilities/providers of abortion services

Aware of any public sector facility (District Hospital, RH, PHC)

Aware of any private sector facility

Aware of other providers of abortion services

Knowledge of sex-selective abortion (\%)

Aware that it is possible to determine the sex of the foetus

Has heard of someone who underwent sex-selective abortion ${ }^{1}$

Knows a place where sex-determination tests are performed ${ }^{1}$

Sources of information about abortion (\%)

Mass media

$\mathrm{IPC}^{2}$ or group meetings

IPC

At least any one of the above sources

Note: All Ns are unweighted.

${ }^{1}$ Of those who were aware that sex-determination is possible $(N=2,267)$.

${ }^{2}$ Includes health care providers. 
or very common in their community. Moreover, many knew or had heard of someone who had obtained a sex-selective abortion.

As far as sources of information-both formal and informal_about abortion are concerned, findings highlight that one-fifth of the respondents (19\%) had obtained information in the year preceding the interview through interpersonal contacts (IPC), group meetings or the media, and one-quarter $(26 \%)$ had discussed abortion with family or friends in the year preceding the interview.

\section{Prevalence and experiences of abortion}

Data were collected on the experience of abortion over the course of the woman's lifetime. In addition, using a reproductive life-event calendar, we recorded month-wise information on reproductive events, including abortions experienced over the five years preceding the interview. Findings relating to lifetime experience of abortion as well as abortions experienced during the three years prior to the endline interview, so as to capture the period during which the intervention was conducted and a comparable period prior to the baseline survey are summarised in Table 2.11.

Findings show that in the sampled districts, $13 \%$ of all women interviewed had experienced one or more abortions over their lifetime and 5\% had experienced an abortion in the three years prior to the interview. The abortion ratio ranged from seven per 100 live births over the course of women's life, to 13 per 100 live births in the three years prior to the interview. These ratios are comparable with those obtained in previous community-based studies of abortion among rural women elsewhere in the country (Elul et al., 2004; Ganatra et al., 2008; Malhotra et al., 2003; Saha, Duggal and Mishra, 2004).

Findings suggest that considerable proportions of women underwent a second trimester abortion, had experienced more than one abortion, had sought pregnancy termination from an unqualified provider and had made more than a single attempt to terminate the last pregnancy. Over one-quarter (27\%) of all abortion-seekers and $21 \%$ of those who had undergone an abortion in the three years prior to the interview reported that they had done so in their second trimester of pregnancy. Repeat abortions were fairly common: Indeed, of those women who had ever experienced an abortion or had undergone an abortion in the three years prior to the interview, $18 \%$ had undergone more than one abortion over the course of their life. In addition, a number of women who had ever or recently experienced an abortion-11\% and $16 \%$, respectively - had attempted to induce the abortion themselves or with the help of a family member or friend, or had approached an informal or untrained provider, including nurses/ANMs and chemists. Successful abortions had been performed, for the most part, by doctors; however, $4 \%$ of women who had ever had an abortion and 5\% of those who had experienced an abortion in the three years preceding the interview reported that their pregnancy had been terminated by a nurse/ANM or traditional practitioner or with medicines supplied by a chemist.

The majority of women who had ever or recently experienced an abortion had undergone 
Table 2.11

Prevalence and experiences of women who had experienced abortion, Aurangabad and Jalna districts, Maharashtra

\begin{tabular}{|c|c|c|}
\hline & Lifetime & $\begin{array}{l}\text { During last three } \\
\text { years }\end{array}$ \\
\hline Number of women & 2,647 & 2,647 \\
\hline \multicolumn{3}{|l|}{ Prevalence of abortion } \\
\hline Women experienced abortion (\%) & 12.8 & 5.1 \\
\hline Abortion ratio (number of abortion per 100 live births) & 6.8 & 12.8 \\
\hline Number of women who experienced abortion & 345 & 138 \\
\hline \multicolumn{3}{|l|}{ Experiences (\%) } \\
\hline Women reporting second trimester abortions & 27.4 & 21.2 \\
\hline Women reporting multiple abortions & 18.3 & 18.2 \\
\hline Women who sought termination from an untrained individual ${ }^{1}$ & 10.9 & 15.6 \\
\hline \multicolumn{3}{|l|}{ Women whose abortion was conducted by: (\%) } \\
\hline Public sector doctor & 10.6 & 8.0 \\
\hline Private doctor & 85.3 & 86.9 \\
\hline Nurse/ANM, chemist, traditional practitioner & 4.1 & 5.1 \\
\hline \multicolumn{3}{|l|}{ Abortion method used (\%) } \\
\hline Surgical methods & 80.5 & 80.1 \\
\hline Medical abortion & 9.4 & 11.8 \\
\hline Injections & 7.7 & 5.9 \\
\hline Vaginal herbs/roots/foreign bodies/homemade concoctions & 1.5 & 0.7 \\
\hline Ayurvedic medicines & 0.9 & 1.5 \\
\hline \multicolumn{3}{|l|}{ Post-abortion contraception (\%) } \\
\hline Adopted post-abortion contraception & 51.0 & 52.7 \\
\hline Adopted a permanent method & 15.3 & 10.2 \\
\hline Adopted any modern non-terminal method & 31.9 & 38.0 \\
\hline \multicolumn{3}{|l|}{ Physical access to facilities and providers (\%) } \\
\hline Travelled for more than an hour to reach the facility or provider & 42.0 & 41.8 \\
\hline \multicolumn{3}{|l|}{ Quality of care $(\%)^{2}$} \\
\hline Very satisfied with the provider & 31.9 & 26.8 \\
\hline Would seek abortion services again if needed/recommend to others & 78.1 & 79.5 \\
\hline Provider gave enough time to respondent to explain her problem & 82.7 & 81.7 \\
\hline Provider gave enough privacy to respondent & 86.6 & 87.0 \\
\hline Provider talked about post-abortion contraception & 37.0 & 40.2 \\
\hline Provider did not require husband's consent & 4.6 & 5.3 \\
\hline $\begin{array}{l}\text { Provider or facility did not force the woman to accept } \\
\text { contraception as a condition for abortion }\end{array}$ & 93.7 & 93.2 \\
\hline \multicolumn{3}{|l|}{ Cost incurred for the abortion procedure and provider fees $(\%)^{3}$} \\
\hline No charge & 1.8 & 1.5 \\
\hline$>$ Rs 500 & 65.3 & 65.4 \\
\hline$>$ Rs 1,000 & 39.8 & 35.3 \\
\hline
\end{tabular}

Note: All Ns are unweighted.

${ }^{1}$ Includes themselves, a family member or friend, or an informal or untrained provider, including Nurses/ANMs and chemist.

${ }^{2}$ Excludes women who obtained medication directly from a chemist and used it to successfully terminate the pregnancy.

${ }^{3}$ Excludes women whose abortion was conducted by self, a family member or friend. 
surgical abortion ( $81 \%$ and $80 \%$, respectively). In order to probe whether the woman had undergone D\&C or MVA, we asked whether she was administered general anaesthesia (suggesting D\&C) or whether the abortion was conducted using a syringe or 'pichkari' (suggesting MVA): findings suggest that the majority had undergone D\&C. In contrast, just $9 \%$ and $12 \%$ of women, respectively, who had ever or recently undergone an abortion reported a medical abortion. In addition, $6-8 \%$ reported that their abortion had been conducted using injections, and the remaining $2 \%$ by traditional methods.

Post-abortion contraception was far from universal; for example, just half of the women who had experienced abortion in the three years prior to the interview had adopted contraception following their abortion. Leading methods adopted were female sterilisation and such non-terminal methods as the condom and oral contraceptives. Those who had adopted contraception differed from those who had not in significant ways: they were more likely to have received counselling, to be older, to have at least one surviving son and to come from better-off households (not shown in table).

A number of obstacles appeared to inhibit access to abortion services and affect the quality of the experience. For example, physical access to facilities and providers was difficult; more than twofifths of women in the study sites reported that they had travelled for more than an hour to reach the facility in which their abortion had been conducted.

Second, several concerns persist with regard to the quality of care experienced by women. For example, just between three-quarters and four-fifths of women reported that they had been given enough information, time and privacy by the provider, and that they would return to the same facility if they needed an abortion in the future or would recommend the provider to others. Worse, just $27-32 \%$ of the women who had ever or recently (in the three years preceding the interview) experienced an abortion reported that the experience was very satisfactory. Moreover, the large majority reported that the provider had required the consent of their husband, a condition not required under the Act, and just $37-40 \%$ reported that the provider had counselled them about adopting a method of contraception. Small but disturbing minorities of women-6-7\%-reported that the provider or facility had forced them to adopt a method of contraception as a condition for providing the abortion. Finally, abortion costs were significant: as many as $65 \%$ of the women had paid more than Rs 500 and $35-40 \%$ had paid more than Rs 1,000; just $2 \%$ reported that the procedure had been conducted completely free of charge. 


\section{CHAPTER 3}

\section{The Comprehensive Abortion Care model}

The Consortium for Safe Abortions in India, as mentioned earlier, comprises several major players in the abortion field in the country. Its main goal is to increase poor rural women's access to legal, safe and comprehensive abortion services, including post-abortion family planning, in the public health system. With this aim, a district level Comprehensive Abortion Care (CAC) model implemented at both health system and community levels was developed and piloted in Aurangabad district of Maharashtra state by Ipas, one of the seven members of the Consortium. The model aimed at addressing both health system and community level barriers to safe abortion, thereby enabling public sector sites to offer comprehensive abortion care services and simultaneously, building awareness among and empowering poor rural women to access safe and good quality abortion services.

This chapter describes the objectives of the intervention, its design, its main components, and challenges faced-both at the health system and community levels_-in its implementation.

\section{Objectives}

As mentioned above, the CAC model was twopronged-at the facility and community levels. More specifically, at the facility level, the objectives were to facilitate service delivery at public sector sites by enhancing the capacity of PHCs and RHs (and, to a lesser extent, the District Hospital) to deliver comprehensive abortion services. Activities at the facility level included the training of providers, ensuring the availability of equipment and regular supplies, and regular monitoring of programme activities. At the community level, the model aimed to increase, among women and men, awareness of the legality, safety and availability of abortion services in the community, sensitise communities to the importance of early termination of pregnancy, the dangers of unsafe or late abortion, the availability of newer and safer methods of abortion (MVA/MA), and the location of safe abortion services, especially those in the public sector.

The intervention was implemented in partnership with the Department of Health and Family Welfare, Government of Maharashtra. Indeed, the state government covered the costs of a number of the facility-level activities, including the training of providers, and the upgrading of the general infrastructure of the selected facilities and the provision of equipment at these facilities. The Consortium's role was to provide technical support and monitoring of activities and to raise community-level awareness about the legality of abortion and the availability of safe abortion services in the public sector.

\section{Setting}

The intervention in Maharashtra focused on Aurangabad district. Specifically, facility-level activities were conducted in 32 public sector sites - 23 of the 50 PHCs and all nine RHs of the district (Table 3.1). Community-level activities were conducted in the villages served by these sites. Selection of the sites was made by Ipas on the 


\section{Table 3.1}

Distribution of PHCs and RHs under study, Aurangabad and Jalna districts, Maharashtra

\begin{tabular}{l|c|c|c|c|}
\multirow{2}{*}{} & \multicolumn{2}{|c|}{ Aurangabad } & \multicolumn{2}{c}{ Jalna } \\
\cline { 2 - 5 } & Baseline & Endline & Baseline & Endline \\
\hline PHCs & $\mathbf{5 0}$ & 45 & 37 & - \\
Intervention & 23 & 21 & - & - \\
Non-intervention & 27 & 24 & 10 & 10 \\
RHs & 9 & 14 & - & - \\
Intervention & 9 & 11 & - & - \\
Non-intervention & - & 3 & & -
\end{tabular}

strength of the findings of the baseline facility study; the selection of facilities was made purposively, based on their greater readiness for abortion services as measured by three major criteria-infrastructure availability, current service provision, and availability of trained providers (for more details, see Kalyanwala, Zavier and Jejeebhoy, 2010).

By the time of the endline survey, some changes had taken place in the classification of PHCs and RHs. In Aurangabad district, five facilities classified as PHCs at the time of the baseline survey were upgraded to RHs; hence, at endline, there were 45 PHCs (21 and 24 in intervention and non-intervention areas, respectively) and 14 RHs (11 and three in intervention and non-intervention areas, respectively). In Jalna, the control site, there were 37 PHCs and $10 \mathrm{RHs}$ at the time of the baseline survey. By the time of the endline survey, two additional PHCs had been created and, as such, there were 39 PHCs and, as before, 10 RHs.

\section{Implementation}

Intervention activities were launched in two phases across the identified public sector facilities and the villages served by these facilities. Activities were conducted at both facility and community levels: facility-level activities were conducted between January 2008 and December 2009, and communitylevel activities over approximately 15 months, starting in October 2008 and ending in December 2009.

\section{Facility-based intervention}

In order to facilitate service delivery at the selected public sector facilities the intervention focused on building partnerships between the implementing agency and state and district government officials, strengthening facilities, and building a cadre of trained abortion providers.

With a view to build ownership of the model, extensive efforts were made to involve state and district government representatives in the development and implementation of project activities. Meetings were held with key government officials to solicit their support and inputs in the final design of the intervention project. A districtlevel core committee was constituted to jointly determine project planning, implementation support 
and monitoring. In fact, this committee played a significant role in the roll out of the project, reviewing project progress on a regular basis, and addressing issues and concerns in training and service delivery. Notably, even though the project has come to an end, the core committee continues to meet and deliberate on steps needed to continue CAC service delivery.

In order to strengthen the selected service delivery sites to provide quality services in partnership with the district authorities, inventories of available and required infrastructure, equipment and supplies were prepared and efforts were made to provide the necessary equipment and supplies such as MTP instruments, MVA kits, screens for privacy, equipment for infection control measures and so on, and to ensure a regular supply of consumables.

Perhaps the most critical aspect of the CAC model was conducting activities to fill the shortfall of trained abortion providers in PHCs and RHs. With a view to create a cadre of abortion providers, two facilities were identified, strengthened and upgraded into training centres for abortion service providers. In order to strengthen the skills of staff at these sites and create a cadre of master trainers, a first activity was to train trainers. Manuals and instruction guides covering all aspects of CAC_-clinical as well as non-clinical components-were prepared for master trainers. Manuals and guides were also prepared for obstetricians/gynaecologists, MBBS doctors and nursing staff. Using these guides, orientation training programmes were held for obstetricians/gynaecologists to acquaint them with new technologies and skills in providing comprehensive abortion services, training programmes were held for MBBS doctors in order to certify them as providers of abortion services, and for nursing staff to support abortion services and provide relevant non-clinical services. Further, to ensure that the providers could start service delivery post training, each doctor was given an MVA kit on the successful completion of the training. Subsequently, the government took on the task of providing kits to public sector doctors trained by the intervention, another indicator of government commitment to comprehensive abortion care.

Activities were overseen and monitored extensively by Ipas representatives. Inputs included mentoring during training programmes; providing on-site support as well as tracking CAC service delivery at each selected facility with the intention of improving service quality and ensuring the submission of monthly reports.

By the end of the implementation phase, a total of 33 obstetricians/gynaecologists had been trained as Master Trainers; eight obstetricians/ gynaecologists and $42 \mathrm{MBBS}$ doctors had been trained and certified to provide CAC services, 38 nursing staff had been trained in non-clinical aspects of CAC service delivery, and 32 PHCs and RHs had been strengthened.

\section{Community-based intervention}

At the community level, a multi-pronged Behaviour Change Communication (BCC) strategy was developed and implemented to increase awareness of the legality, safety and availability of abortion services; to increase use of safe abortion services, particularly in the public sector among women facing an unwanted pregnancy, and to build a 
positive environment, more generally, on the topic of safe abortion. BCC campaign activities ranged from interpersonal communication to group meetings, street plays and distribution of easy-to-understand reference materials. The BCC strategy was implemented through two local NGOs in villages covered by seven blocks of the district, namely, Aurangabad, Paithan, Sillod, Vaijapur, Kannad, Khultabad and Gangapur.

As in the case of facility-based activities, the communication strategy, content and materials were developed in partnership with state- and district-level government representatives, including the state IEC Bureau as well as the two implementing NGOs. The communication campaign centred on a young woman named "Kalyani" and all booklets, posters and wall paintings focused on Kalyani's situation; she was, in a sense, the protagonist of the BCC strategy. A range of materials was prepared, including leaflets and information booklets designed specifically for neo-literate women and scripts for street plays, using local terminology. The scripts highlighted the need for accessing safe abortion services, and the dangers of accessing abortion from untrained providers or undergoing second trimester abortion. All communication materials were pre-tested prior to their use in the community. Intervention activities targeted women aged 15-49, men aged 18-49 and village level health workers.

As the activities were conducted through the two local NGOs, a first step involved intensive training of NGO field staff who would be responsible for implementing the communication strategy. An intensive training programme, conducted over two days, familiarised NGO field staff with the basic aspects of CAC, sharpened their skills in interpersonal communication and group facilitation, introduced them to the outdoor and interpersonal communication materials developed by the project, and trained them in using these tools in the course of BCC activities.

The BCC strategy also involved such fieldlevel health care providers as ANMs, AWWs and Traditional Birth Attendants (TBAs) who were oriented through group meetings by the implementing NGOs on issues related to unsafe abortion. They were also provided reference booklets on safe abortion, given information on facilities in which legal and safe abortion services were available, and trained to refer women in need of abortion to these facilities. Through the project period, about 1300 such village-level health care workers were thus sensitised to abortion-related issues and informed about appropriate facilities for safe abortion services.

BCC activities were conducted at various levels, most using Kalyani as the protagonist. They included group meetings with women's self-help groups and community members more generally, and one-on-one meetings with women. Most interactions were interactive, and included discussions, stories, games, street plays and so on. In total, NGO reports suggest that the focus of all these activities was on enabling communities to better appreciate the dangers of unsafe abortion and the importance of obtaining timely abortions from appropriate facilities; at the same time, they also conveyed information on recognition of symptoms of pregnancy, steps to be taken once the pregnancy is diagnosed and use of contraception. 
Street plays, using local terminology, attracted large numbers of community members, while wall paintings and posters provided information on the legality and availability of safe abortion services, new techniques of abortion (MVA/MA) and dangers of unsafe abortion in addition to short pertinent messages describing the action to be taken in case of an unwanted pregnancy. Monitoring data from NGO partners and Ipas suggest that in total, over 2,00,000 contacts were made, 4,300 group meetings were held, 800 wall paintings were displayed, more than 5,000 posters were distributed and 760 street plays were conducted.

Finally, while communication via the mass media was not part of the original BCC strategy, local print media were leveraged to provide news coverage and spread messages on safe abortion. A number of leading Marathi newspapers, including Lokmat, Loksatta and Sakal, covered the campaign spontaneously, thereby serving as an unexpected means through which communication was effected.

\section{Challenges}

Several challenges were faced in the course of project implementation. For one, while the partnership with district government representatives was central, the relatively frequent transfer of key government officials in the core committee affected the continuity of leadership, and required orienting new officials about the CAC model and addressing their concerns about its relevance.

Second, the model confronted several obstacles to improving the availability of services at PHC and $\mathrm{RH}$ levels. For example, the frequent transfers of doctors trained by the intervention meant that several trained doctors were shifted out of the district, or to a facility within the district that did not contain the necessary equipment for providing abortions. Also impeding the pace at which provider training occurred was the fact that trainers were not available on a regular basis. Provider attitudes posed yet another hurdle: it was difficult to convince many doctors that MVA and MA are far superior techniques of abortion than is D\&C. Finally, the absence of basic amenities and facilities-from water to essential equipment-posed a huge challenge, and affected the pace at which the upgrading of facilities to provide abortion was conducted. The project made concerted efforts to overcome these challenges, and local government officials played a considerable role in supporting the project in doing so.

Challenges were also encountered in the course of implementing community-level activities. For one, it was difficult to assemble women and/ or communities to attend group meetings, street plays and other gatherings, resulting, on occasion, in sparse attendance at these events, and requiring more of a focus on interpersonal contacts. At the same time, because of general perceptions of the poor quality of services, long waiting times and frequent re-visit requirements at public sector facilities, the project experienced considerable difficulty in promoting the use of public sector facilities for abortion. Finally, it is not clear whether this generalised community-based approach to enhancing abortion-related awareness succeeded in reaching those most in need, that is, those in the childbearing ages and those with an unmet need for contraception. 


\section{CHAPTER 4}

\section{Intervention effects on the health system}

This chapter assesses the extent to which exposure to the CAC model did indeed affect PHC and $\mathrm{RH}$ readiness to provide comprehensive abortion care. Several changes that occurred at the health system level cannot be attributed to the intervention, for example, those relating to general infrastructure, staffing patterns and provision of reproductive health services other than abortion. The intervention sought to make changes in specific aspects of the health system, such as, for example, the availability of (a) safe abortion services; (b) trained abortion service providers; (c) IEC materials relating to abortion, relative to information available on other aspects of reproductive health; (d) abortion-related infrastructure, equipment and supplies; and (e) abortion-related services of good quality. This chapter also offers comparisons across districts as well as across intervention and non-intervention facilities (as relevant) in Aurangabad, the intervention district. Intervention effects are measured in terms of changes in various process indicators.

There is no doubt that the general situation of health facilities had improved in both districts. Over the two years during which the intervention was conducted, the number of PHCs in Aurangabad declined from 50 to 45 , as five PHCs were upgraded to RHs, taking the number of RHs in Aurangabad from nine to 14. In Jalna, in contrast, while two PHCs were added over the three-year period (from 37 to 39), the number of RHs remained unchanged at 10 . At the same time, many facilities experienced improvements in their general infrastructure and availability of services—-many affected by our intervention-that influenced the provision of abortion services in the public sector in Aurangabad relative to Jalna.

\section{Availability of abortion services}

Findings confirm that a range of reproductive and child health services were offered by all RHs and almost all PHCs (Table 4.1). Indeed, at the PHC level (Panel A, Table 4.1), antenatal and postpartum care services and non-terminal contraception services were offered universally at the time of both surveys; delivery services, available in just $84 \%$ and $76 \%$ of PHCs in Aurangabad and Jalna, respectively, at baseline, became almost universally available by the time of the endline survey (92-96\%). In contrast, fewer PHCs provided sterilisation services: the percentage of PHCs providing tubal ligation increased modestly in Aurangabad and fell modestly in Jalna, while the percentage offering vasectomy fell in Aurangabad and increased modestly in Jalna. At the RH level (Panel B, Table 4.1), almost all services were universally available at both points in time; the only exception was vasectomy services: the number of RHs providing vasectomy increased from nine to 11 in Aurangabad and fell from four to three in Jalna.

While district-wise differences in the abovementioned reproductive health services were modest, differences in abortion services were stark, clearly showing the influence of the intervention (Table 4.1). For example, as shown in Panel A, while at baseline, not a single PHC in Aurangabad and 
Table 4.1

Constellation of services provided at PHCs and RHs, Aurangabad and Jalna districts, Maharashtra

\begin{tabular}{|c|c|c|c|c|c|c|c|c|}
\hline & \multicolumn{6}{|c|}{ Aurangabad } & \multicolumn{2}{|c|}{ Jalna } \\
\hline & \multicolumn{3}{|c|}{ Baseline } & \multicolumn{3}{|c|}{ Endline } & \multirow{2}{*}{$\frac{\text { Baseline }}{\text { Total }}$} & \multirow{2}{*}{$\frac{\text { Endline }}{\text { Total }}$} \\
\hline & Total & $\begin{array}{l}\text { Non- } \\
\text { interven- } \\
\text { tion }\end{array}$ & $\begin{array}{l}\text { Interven- } \\
\text { tion }\end{array}$ & Total & $\begin{array}{l}\text { Non- } \\
\text { interven- } \\
\text { tion }\end{array}$ & $\begin{array}{l}\text { Interven- } \\
\text { tion }\end{array}$ & & \\
\hline A. PHC level (\%) & & & & & & & & \\
\hline $\begin{array}{l}\text { Number of PHCs } \\
\text { Constellation of services } \\
\text { provided }\end{array}$ & 50 & 27 & 23 & 45 & 24 & 21 & 37 & 39 \\
\hline $\begin{array}{l}\text { ANC and postpartum } \\
\text { services }\end{array}$ & 100.0 & 100.0 & 100.0 & 100.0 & 100.0 & 100.0 & 100.0 & 100.0 \\
\hline Delivery services & 84.0 & 70.4 & 100.0 & 95.6 & 91.7 & 100.0 & 75.7 & 92.3 \\
\hline Provision of contraception & 100.0 & 100.0 & 100.0 & 100.0 & 100.0 & 100.0 & 100.0 & 100.0 \\
\hline $\begin{array}{l}\text { Non-terminal contraceptive } \\
\text { methods (condom, oral } \\
\text { contraceptive, IUD) }\end{array}$ & 100.0 & 100.0 & 100.0 & 100.0 & 100.0 & 100.0 & 100.0 & 100.0 \\
\hline Tubal ligation & 72.0 & 48.1 & 100.0 & 82.2 & 66.7 & 100.0 & 56.8 & 46.2 \\
\hline Vasectomy & 62.0 & 40.7 & 87.0 & 51.1 & 33.3 & 71.4 & 10.8 & 15.4 \\
\hline $\begin{array}{l}\text { MTP services } \\
\text { Currently available } \\
\text { (three months preceding } \\
\text { the interview) }\end{array}$ & 0.0 & 0.0 & 0.0 & 33.3 & 12.5 & 57.1 & 2.7 & 23.1 \\
\hline B. RH level (n) & & & & & & & & \\
\hline $\begin{array}{l}\text { Number of RHs } \\
\text { Constellation of services } \\
\text { provided }\end{array}$ & 9 & - & 9 & 14 & 3 & 11 & 10 & 10 \\
\hline $\begin{array}{l}\text { ANC and postpartum } \\
\text { services }\end{array}$ & 9 & - & 9 & 14 & 3 & 11 & 10 & 10 \\
\hline Delivery services & 9 & - & 9 & 14 & 3 & 11 & 10 & 10 \\
\hline Provision of contraception & 9 & - & 9 & 14 & 3 & 11 & 10 & 10 \\
\hline $\begin{array}{l}\text { Non-terminal contraceptive } \\
\text { methods (condom, oral } \\
\text { contraceptive, IUD) }\end{array}$ & 9 & - & 9 & 14 & 3 & 11 & 10 & 9 \\
\hline Tubal ligation & 9 & - & 9 & 14 & 3 & 11 & 10 & 8 \\
\hline Vasectomy & 9 & - & 9 & 11 & 1 & 10 & 4 & 3 \\
\hline MTP services & & & & & & & & \\
\hline $\begin{array}{l}\text { Currently available } \\
\text { (three months preceding } \\
\text { the interview) }\end{array}$ & 2 & - & 2 & 13 & 2 & 11 & 3 & 4 \\
\hline
\end{tabular}


just 3\% of those in Jalna were providing abortion services, this percentage increased considerably in Aurangabad (to 33) and less so in Jalna (to 23).

Differences were also apparent at the $\mathrm{RH}$ level (Panel B, Table 4.1). While at baseline, just two of Aurangabad's nine RHs were providing abortion services, almost all-13 of 14-were providing abortion services at the time of the endline survey. In contrast, the situation remained virtually unchanged in Jalna, with abortion services provided in three of the 10 facilities at baseline, increasing by just one by the time of the endline survey.

A comparison of intervention and nonintervention facilities in Aurangabad further underscores the contribution of the intervention. Findings suggest that intervention facilities were more likely than non-intervention facilities to provide such services as delivery, tubal ligation and vasectomy (a result of the purposive facility selection strategy described earlier), and these differences narrowed considerably between the time of the baseline and endline investigations. What clearly differed was the availability of abortion services: while they were not offered at any PHC at baseline, they were offered at more than half (57\%) of intervention PHCs at endline (12 of 21) compared to just one in eight (three of 24) nonintervention PHCs (Panel A, Table 4.1). At the time of the endline survey, moreover, the single $\mathrm{RH}$ not providing abortion services was among the nonintervention facilities (Panel B, Table 4.1).

The staff position at PHC and RH levels is presented in Table 4.2. Findings indicate that all PHCs had at least one medical officer at the time of both base- and end-line surveys, and the mean number of medical officers per PHC increased similarly in both districts, from 1.6 at baseline to 1.8-1.9 at endline (Panel A, Table 4.2). Medical officers were, by and large, male and while the percentage of female medical officers remained virtually unchanged in Aurangabad (36-38), it increased modestly in Jalna (from 16 to 23). In contrast, the percentage of PHCs with the minimum required number of nursing staff (at least four) as per Government of India norms, fell in both districts: modestly in Aurangabad (from 88 to 71) and sharply in Jalna (from 97 to 46).

At the RH level too (Panel B, Table 4.2), between the baseline and endline surveys, the mean number of doctors available at each facility in both districts increased from 5.9 to 6.6 in Aurangabad, and from 4.1 to 5.9 in Jalna. While each facility had at least one medical officer at both base- and end-line, there was little change in the number of facilities with a female medical officer. However, the number of specialists increased more consistently in the RHs in Aurangabad than in Jalna: for example, the number of RHs in which an obstetrician/ gynaecologist was available increased from four to ten in Aurangabad but remained virtually unchanged (from seven to six) in Jalna; at the same time, the number of facilities with a surgeon fell from six to five in Aurangabad but increased from two to eight in Jalna. As far as nursing staff are concerned, as in the case of PHCs (Panel A, Table 4.2), there was little change in the number of facilities with nine or more nursing staff, but there was a decline in the mean number of staff per facility (from 12 to 10 in Aurangabad and from eight to five in Jalna). 
Table 4.2

Availability of trained abortion providers at PHCs and RHs, Aurangabad and Jalna districts, Maharashtra

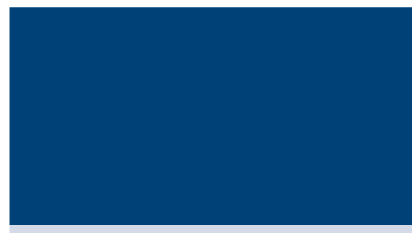

A. PHC level (\%)

Number of PHCs

Availability of doctors

Mean number of doctors

Facilities with at least:

One medical officer

One female doctor

One MTP-certified doctor $^{1}$

Availability of nursing staff

PHCs with at least four nursing staff

Mean number of nursing staff

\section{B. RH level (n)}

Number of RHs

Availability of doctors

Mean number of doctors

Facilities with at least:

One medical officer

One female doctor

One MTP-certified doctor

One specialist

Four specialists

One obstetrician/ gynaecologist

One surgeon

Availability of nursing staff

Nine or more

Mean number of nursing staff

\begin{tabular}{|l|}
\hline \\
\hline Total \\
\hline
\end{tabular}

Baseline

Non-

interven-

tion

\section{Aurangabad}

Aurangabad

Inte

Interven-
tion

Total

Endline

Noninterven-

tion

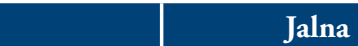

In

Interven-

tion

Baseline Endline

Total Total

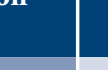

(n)

(2)

50

1.6

27

23

45

1.5

1.7

1.9

100.0

100.0

38.0

6.0

14.8

100.0

65.2

3.7

8.7

35.6

46.7

29.2

29.2

24

21

37

2.0

1.9

1.6

1.8

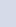

88.0

6.7

85.2

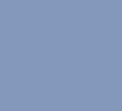

6.3

91.3

7.2

9

5.9

9

5

8

4

4

6

6

11.6

11.6

10.4

100.0

100.0

100.0

16.2

00.0

42.9

66.7

16.2

38.5
${ }^{1}$ In addition, one doctor posted at a PHC in Aurangabad at the time of the baseline survey, and three doctors posted at PHCs in Aurangabad and Jalna, respectively, at the time of the endline survey, reported that they had received MTP training but had not been certified. 
Against this backdrop, the availability of MTPcertified providers increased significantly over the intervention period, particularly in Aurangabad. At the PHC level (Panel A, Table 4.2), facilities with at least one MTP-certified provider registered an eightfold increase in Aurangabad-from 6\% at baseline to $47 \%$ at endline; in contrast, such facilities increased from $16 \%$ to $38 \%$ in Jalna. At the RH level (Panel $\mathrm{B}$, Table 4.2), the number of facilities with a certified MTP provider increased from five to 13 in Aurangabad; indeed, all but one RH had a certified MTP provider by the time of the endline survey. In contrast, the situation remained virtually unchanged in Jalna, where almost all RHs contained a certified provider even at baseline (from nine to eight).

A comparison of intervention and nonintervention facilities in Aurangabad again underscores the contribution of the intervention. While hardly any PHC had a trained MTP provider at the time of the baseline survey, two in three intervention PHCs, compared to fewer than one in three non-intervention facilities had a trained MTP provider by the time of the endline survey (Panel A, Table 4.2).

\section{Provider awareness and perceptions}

Provider awareness about abortion-related issues, by and large, increased more consistently in Aurangabad than in Jalna over the period of the intervention (Table 4.3). For example, among PHC- and RHlevel medical officers in Aurangabad, awareness that MA is provided only up to seven weeks of gestation increased by 13 percentage points, that the opinion of more than one registered doctor is required for second trimester abortion by 24 percentage points, and that the consent of the husband or guardian is not necessary to conduct abortions of women aged 18 and above by 21 percentage points. In contrast, awareness levels among medical officers in Jalna were inconsistent and moderate. Awareness about all of four key aspects of abortion (that MA is provided only up to seven weeks of gestation, that only MTPcertified providers can prescribe MA, that second trimester abortion requires the opinion of two doctors, and that the husband's or guardian's consent is not required for abortion) was more pronounced in Aurangabad (an increase of 29 percentage points) than in Jalna (an increase of 1 point). Differences in awareness among medical officers who were certified and uncertified to provide abortion were wide in Aurangabad (70\% versus 31\% were aware of all four of the above legal requirements for abortion) and relatively narrow in Jalna (6 of 17 versus 22\%). Moreover, in Aurangabad, while about one-fifth of all providers from both intervention and nonintervention facilities were aware of all four of the above legal requirements for abortion at the time of the baseline survey, the increase in awareness was greater in intervention than non-intervention facilities, with $53 \%$ and $44 \%$, respectively, reporting such awareness.

Provider perceptions about women's right to confidential counselling and to be informed about the procedure she is to undergo had, however, become virtually universal in both districts over the period of the intervention. 
Table 4.3

Awareness among PHC- and RH-level medical officers about MTP and their perceptions about abortion and women's abortion-related rights, Aurangabad and Jalna districts, Maharashtra

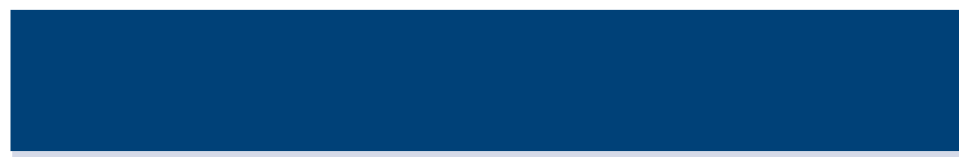

\begin{tabular}{|c|c|}
\multicolumn{2}{|c|}{ Aurangabad } \\
\hline Baseline & Endline \\
\hline Total & Total \\
\hline
\end{tabular}

\begin{tabular}{|c|c|}
\hline \multicolumn{2}{|c|}{ Jalna } \\
\hline Baseline & Endline \\
\hline Total & Total \\
\hline
\end{tabular}

Number of PHC- and RH-level medical officers

\begin{tabular}{|r|r|r|r|}
\hline $\mathbf{5 4}$ & $\mathbf{5 9}$ & $\mathbf{4 3}^{\mathbf{1}}$ & $\mathbf{4 9}$ \\
\hline 83.3 & 96.6 & 90.7 & 93.9 \\
\hline 77.8 & 79.7 & 76.7 & 63.3 \\
\hline 53.7 & 78.0 & 62.8 & 63.3 \\
\hline 48.1 & 69.5 & 53.5 & 61.2 \\
\hline 20.4 & 49.2 & 25.6 & 26.5 \\
\hline$(1)$ & 70.3 & $(4)$ & $(6)$ \\
\hline 20.8 & 31.3 & 21.2 & 21.9 \\
\hline 21.7 & 44.4 & - & - \\
\hline 19.4 & 53.1 & - & - \\
\hline 85.2 & 96.6 & 88.4 & 89.8 \\
\hline 75.9 & 96.6 & 62.8 & 98.0 \\
\hline
\end{tabular}

Awareness: \% aware that:

MA is provided only up to 7 weeks of gestation

Only MTP-certified MBBS doctors are permitted to prescribe MA

The opinion of more than one registered doctor is required for abortions performed between 12-20 weeks of pregnancy

Consent of husband (or guardian) for abortion is not required for women aged 18 and above

Aware of all 4 of the above
All providers
Certified providers ${ }^{2}$
Uncertified providers ${ }^{3}$
Providers at non-intervention facilities ${ }^{4}$
Providers at intervention facilities 5

Perceptions about women's rights: $\%$ who perceive that women should:

Undergo counselling privately

Be fully informed about the specifics of the medical procedure she is to undergo

${ }^{1}$ Information from 5 and 4 PHCs in Aurangabad and Jalna, respectively, was not available.

${ }^{2}$ Number of certified providers at baseline and endline, respectively: 6 and 27 in Aurangabad, 10 and 17 in Jalna.

${ }^{3}$ Number of uncertified providers at baseline and endline, respectively: 48 and 32 in Aurangabad, 33 and 32 in Jalna.

${ }^{4}$ Number of providers in non-intervention facilities at baseline and endline, respectively: 23 and 27.

${ }^{5}$ Number of providers in intervention facilities at baseline and endline, respectively: 31 and 32.

\section{Availability of IEC materials}

As evident from Panel A of Table 4.4, IEC materials were displayed in all PHCs, and here, there was a similar increase in both districts. While almost all PHCs displayed materials on child health at the time of both base- and end-line surveys, there was a consistent increase in the percentages of PHCs in the two districts displaying materials on maternal health (from 68-70 to 90-93) and family planning (from 74 to 98 in Aurangabad and from 87 to 95 in Jalna). A similar general picture was observed at the RH level (Panel B, Table 4.4).

Panel A of the table further indicates that at the PHC level the availability of abortion-related information increased considerably in both settings. At baseline, materials largely focused on the illegality 
of sex-selective abortion, with $52 \%$ and $73 \%$

of PHCs in Aurangabad and Jalna, respectively, reporting their availability; in contrast, just 5-6\% contained materials on the legality and availability of abortion services. By the time of the endline survey, the percentage of PHCs with materials on sexselective abortion remained virtually unchanged, but the percentage reporting materials on the availability and legality of abortion increased considerably in both settings: by 63 percentage points in Aurangabad (6 to 69) compared to 44 percentage points in Jalna (5 to 49 ).

At the RH level, the increase in the availability of abortion-related materials was far more evident

Table 4.4

Availability of IEC materials in PHCs and RHs, Aurangabad and Jalna districts, Maharashtra

\begin{tabular}{|c|c|c|c|c|c|c|c|c|}
\hline & \multicolumn{6}{|c|}{ Aurangabad } & \multicolumn{2}{|c|}{ Jalna } \\
\hline & \multicolumn{3}{|c|}{ Baseline } & \multicolumn{3}{|c|}{ Endline } & \multirow{2}{*}{$\frac{\text { Baseline }}{\text { Total }}$} & \multirow{2}{*}{$\frac{\text { Endline }}{\text { Total }}$} \\
\hline & Total & $\begin{array}{l}\text { Non- } \\
\text { interven- } \\
\text { tion }\end{array}$ & $\begin{array}{l}\text { Interven- } \\
\text { tion }\end{array}$ & Total & $\begin{array}{l}\text { Non- } \\
\text { interven- } \\
\text { tion }\end{array}$ & $\begin{array}{l}\text { Interven- } \\
\text { tion }\end{array}$ & & \\
\hline A. PHC level (\%) & & & & & & & & \\
\hline Number of PHCs & 50 & 27 & 23 & 45 & 24 & 21 & 37 & 39 \\
\hline IEC materials displayed & & & & & & & & \\
\hline $\begin{array}{l}\text { Child health including } \\
\text { immunisation }\end{array}$ & 92.0 & 88.9 & 95.6 & 100.0 & 100.0 & 100.0 & 100.0 & 94.9 \\
\hline Maternal health & 70.0 & 66.7 & 73.9 & 93.3 & 87.5 & 100.0 & 67.6 & 89.7 \\
\hline $\begin{array}{l}\text { Family planning (including } \\
\text { posters, brochures, } \\
\text { samples) }\end{array}$ & 74.0 & 66.7 & 82.6 & 97.8 & 100.0 & 95.2 & 86.5 & 94.9 \\
\hline $\begin{array}{l}\text { Illegality of sex-selection } \\
\text { practices and abortion }\end{array}$ & 52.0 & 37.0 & 69.6 & 55.6 & 37.5 & 76.2 & 73.0 & 66.7 \\
\hline $\begin{array}{l}\text { Legality, availability of } \\
\text { abortion }\end{array}$ & 6.0 & 3.7 & 8.7 & 68.9 & 50.0 & 90.5 & 5.4 & 48.7 \\
\hline B. RH level (n) & & & & & & & & \\
\hline Number of RHs & 9 & - & 9 & 14 & 3 & 11 & 10 & 10 \\
\hline IEC materials displayed & & & & & & & & \\
\hline $\begin{array}{l}\text { Child health including } \\
\text { immunisation }\end{array}$ & 9 & - & 9 & 14 & 3 & 11 & 10 & 7 \\
\hline Maternal health & 8 & - & 8 & 13 & 2 & 11 & 10 & 8 \\
\hline $\begin{array}{l}\text { Family planning (including } \\
\text { posters, brochures, } \\
\text { samples) }\end{array}$ & 9 & - & 9 & 14 & 3 & 11 & 10 & 9 \\
\hline $\begin{array}{l}\text { Illegality of sex-selection } \\
\text { practices and abortion }\end{array}$ & 6 & - & 6 & 13 & 3 & 10 & 10 & 6 \\
\hline $\begin{array}{l}\text { Legality, availability of } \\
\text { abortion }\end{array}$ & 3 & - & 3 & 12 & 1 & 11 & 4 & 6 \\
\hline
\end{tabular}


in Aurangabad than Jalna (Panel B, Table 4.4). In Aurangabad, for example, while just six and three RHs had displayed materials on the Prenatal Diagnostic Techniques (PNDT) Act and the availability of abortion services, respectively, at baseline, almost all (12-13 of the $14 \mathrm{RHs}$ ) had such materials available by endline. In Jalna, in contrast, at these two points in time, there was actually a reduction in the number of facilities displaying materials on the PNDT Act and a slight increase in those displaying information on the availability of abortion services.

A comparison of intervention and nonintervention facilities in Aurangabad again underscores the contribution of the intervention. While percentages of facilities displaying materials on maternal health and family planning were indeed greater at baseline among intervention than non-intervention facilities, and small percentages of both groups $(<10 \%)$ displayed information on the legality and availability of abortion services, increases between baseline and endline in percentages of facilities displaying abortion-related materials were more spectacular in intervention than nonintervention facilities. For example, the percentage of intervention PHCs displaying information about the legality and availability of abortion services increased (from 9 to 91) among intervention facilities, compared to a corresponding increase (from 4 to 50) in the non-intervention facilities (Panel A, Table 4.4). However, the availability of materials related to the illegality of sex-selective abortion increased only moderately from $70 \%$ to $76 \%$ among PHCs in which the intervention was implemented, compared to no change in those in which it was not implemented (37-38\%). A similar pattern was observed among RHs in which the intervention was implemented: information on the legality and availability of abortion services was displayed in three of the nine facilities at baseline and at all 11 intervention facilities at endline (Panel B, Table 4.4).

\section{Infrastructure and equipment}

\section{Facility and examination room infrastructure}

The intervention was not intended to influence the infrastructure of the facility or the examination room; indeed, improvements in infrastructure, for example communication facilities in both districts may be attributed to overall investment by the state in upgrading health facilities. Findings, presented in Table 4.5, therefore, do not distinguish between intervention and non-intervention facilities in Aurangabad; however, we acknowledge that projectrelated time investments and monitoring activities may have had an indirect influence on improving infrastructure in Aurangabad. Findings confirm that infrastructure was more likely to be available in Aurangabad than in Jalna both at baseline and endline, but that improvements over time were far more striking in Aurangabad than in Jalna. At the PHC level (Panel A, Table 4.5), for example, improvements were evident in both districts in the percentages of PHCs with landline telephone and electricity facilities, and access to transportation for emergencies. At the same time, marginal changes were evident in the percentage of PHCs in both districts that recorded fewer than four beds (the 
Table 4.5

Availability of basic infrastructure at PHCs and RHs, Aurangabad and Jalna districts, Maharashtra

\begin{tabular}{|c|c|c|c|c|}
\hline & \multicolumn{2}{|c|}{ Aurangabad } & \multicolumn{2}{|c|}{ Jalna } \\
\hline & Baseline & Endline & Baseline & Endline \\
\hline \multicolumn{5}{|l|}{ A. PHC level (\%) } \\
\hline Number of PHCs & 50 & 45 & 37 & 39 \\
\hline \multicolumn{5}{|l|}{ Basic infrastructure } \\
\hline \multicolumn{5}{|l|}{ Beds available } \\
\hline Mean number of beds & 8.3 & 7.4 & 6.7 & 7.4 \\
\hline Four or more beds & 88.0 & 88.9 & 97.3 & 89.7 \\
\hline \multicolumn{5}{|l|}{ Electricity } \\
\hline Electricity connected & 90.0 & 100.0 & 91.9 & 94.9 \\
\hline \multicolumn{5}{|l|}{ Telephone facility } \\
\hline Landline telephone available & 6.0 & 97.8 & 5.4 & 97.4 \\
\hline At least one staff has a mobile & 94.0 & 100.0 & 94.6 & 97.4 \\
\hline \multicolumn{5}{|l|}{ Water supply } \\
\hline Main source of water supply_-piped water & 56.0 & 68.9 & 48.6 & 41.0 \\
\hline Piped water in toilet & 16.0 & 51.1 & 2.7 & 17.9 \\
\hline \multicolumn{5}{|l|}{ Transport } \\
\hline Can arrange transport at emergency, regularly & 74.0 & 97.8 & 59.5 & 82.1 \\
\hline $\begin{array}{l}\text { Facilities with electricity, at least four beds, piped water and } \\
\text { regular transport facility }\end{array}$ & 50.0 & 55.6 & 32.4 & 25.6 \\
\hline \multicolumn{5}{|l|}{ B. RH level (n) } \\
\hline Number of RHs & 9 & 14 & 10 & 10 \\
\hline \multicolumn{5}{|l|}{ Basic infrastructure } \\
\hline \multicolumn{5}{|l|}{ Beds available } \\
\hline Mean number of beds & 35.4 & 30.7 & 25.1 & 31.0 \\
\hline 30 or more beds & 8 & 10 & 6 & 8 \\
\hline \multicolumn{5}{|l|}{ Electricity } \\
\hline Electricity connected & 9 & 14 & 10 & 10 \\
\hline \multicolumn{5}{|l|}{ Telephone facility } \\
\hline Landline telephone available & 8 & 12 & 5 & 10 \\
\hline At least one staff has a mobile & 9 & 14 & 10 & 10 \\
\hline \multicolumn{5}{|l|}{ Water supply } \\
\hline Main source of water supply-piped water & 7 & 13 & 7 & 6 \\
\hline Piped water in toilet & 6 & 12 & 5 & 5 \\
\hline Transport & & & & \\
\hline Can arrange transport at emergency, regularly & 8 & 14 & 7 & 10 \\
\hline $\begin{array}{l}\text { Facilities with electricity, at least } 30 \text { beds, piped water and } \\
\text { regular transport facility }\end{array}$ & 7 & 10 & 5 & 5 \\
\hline
\end{tabular}


norm). In contrast, while the percentage of PHCs with piped water increased from 56 to 69 in Aurangabad, it declined from 49 to 41 in Jalna. In summary, the percentage of PHCs with electricity, at least four beds, piped water and regular access to transport increased from 50 to 56 in Aurangabad but in fact, declined from 32 to 26 in Jalna.

Higher order facilities were better equipped (Panel B, Table 4.5). Electricity was available in all RHs in both districts at both points in time. The availability of piped water increased considerably in Aurangabad (from 7 to $13 \mathrm{RHs}$ ) but remained unchanged in Jalna (6-7 RHs). Access to transportation increased in both settings, such that by the time of the endline, all facilities in both districts reported such access. Although on average, these facilities contained 30 or more beds (the norm established by the Government of India for $\mathrm{CHCs}$ ), by endline, just 10 of the $14 \mathrm{RHs}$ in Aurangabad and eight of the 10 in Jalna contained at least 30 beds. A summary measure of available infrastructure index-reflecting the availability of electricity, at least 30 beds, piped water and regular access to transport facilities - suggests that in Aurangabad, facilities with all of these amenities increased from seven to 10 in Jalna, no change was evident (five at both times).

As described earlier, in Aurangabad, the selection of facilities for intervention was determined purposively, among other things, by the availability of basic infrastructure, with those showing greater readiness for abortion-related investment more likely than others to be selected. Findings confirm that basic infrastructure was more likely to be available in intervention than non-intervention facilities in
Aurangabad both at baseline and endline. Indeed, by the time of the endline survey, $67 \%$ of the intervention PHCs compared to $46 \%$ of the nonintervention ones contained basic infrastructure (electricity, at least four beds, piped water and regular transport facility) (not shown in table); likewise, basic infrastructure (electricity, at least 30 beds, piped water and regular transport facility) was available in 10 of the 11 intervention RHs and none of the three non-intervention ones (not shown in table).

Table 4.6 presents the situation in the examination room of the PHCs and RHs. Panel A, shows that at the PHC level, 82-93\% reported a separate room for examination at both timeshowever, visual privacy declined in PHCs of both districts (from $84 \%$ to $67 \%$ in Aurangabad and from $78 \%$ to $62 \%$ in Jalna). The availability of other essential infrastructure such as a wash basin with running water increased considerably in Aurangabad (from $18 \%$ to $60 \%$ ) and that of an operating table with stirrups less so (from 62\% to $76 \%$ ), but remained unchanged (wash basin with running water) or declined (operating table with stirrups) in Jalna. In summary, the percentage of facilities with a separate examination room, visual privacy, an operating table with stirrups and a wash basin with running water increased from 14 to 44 in Aurangabad, and remained unchanged in Jalna (13-16\%).

Improvements in examination room infrastructure were less evident among RHs (Panel B, Table 4.6). For example, at the time of the baseline survey, all RHs in both districts had a separate 
Table 4.6

Examination room infrastructure at PHCs and RHs, Aurangabad and Jalna districts, Maharashtra

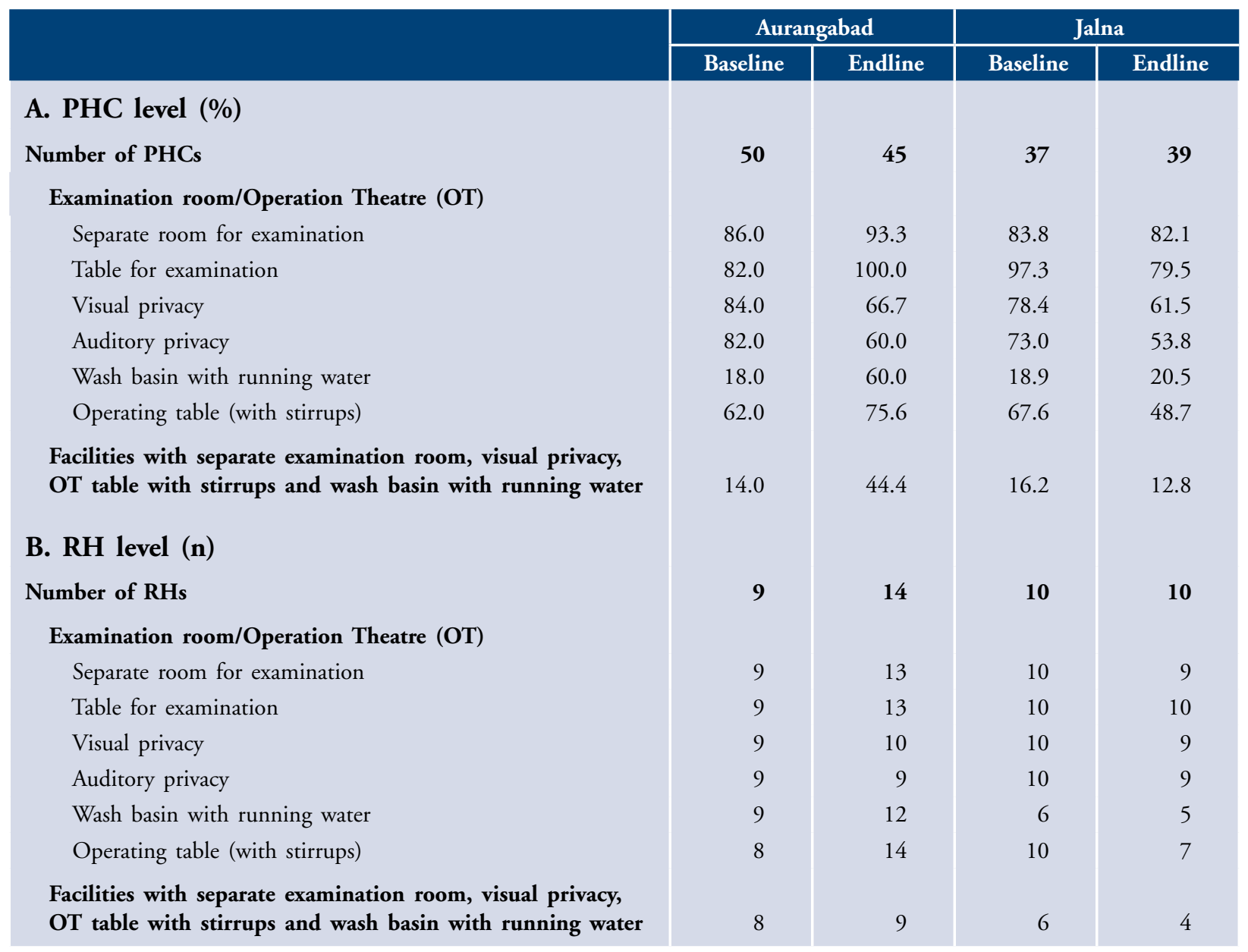

examination room and offered visual privacy; at endline, one or more $\mathrm{RH}$ in each district did not so report. At endline, moreover, two of the $14 \mathrm{RHs}$ in Aurangabad, and five of the 10 in Jalna did not have a wash basin with running water. An operating table with stirrups, seen in almost all RHs in the two districts at baseline, was available in all $14 \mathrm{RHs}$ in Aurangabad, but just seven of the $10 \mathrm{RHs}$ in Jalna at endline. In summary, facilities with a separate examination room, visual privacy, an operating table with stirrups and a wash basin with running water were available in just nine of the 14 facilities in Aurangabad at endline, compared to four of the 10 facilities in Jalna.

As in the case of basic infrastructure, infrastructure in the examination room was also key in the selection of PHCs for intervention, but was not directly influenced by the intervention, 
and hence findings presented in Table 4.6, do not distinguish between intervention and non-intervention facilities in Aurangabad. We acknowledge, however, that examination room infrastructure was more likely to be available in intervention than non-intervention facilities in Aurangabad both at baseline and endline.

\section{Essential equipment for the provision of abortion services}

In contrast to basic and examination room infrastructure, the intervention did indeed seek to enhance the availability of functioning essential equipment for the provision of abortion services. As Table 4.7 shows, there was an impressive increase in the availability of such equipment for the provision of abortion services in both districts, but clearly improvements are more widely observed in Aurangabad than in Jalna.

At the PHC level, for example, in Aurangabad, there was a considerable increase, for the most part in the availability of functioning essential equipment, ranging from MVA suction machines to dilators (Panel A, Table 4.7). Correspondingly, changes over time in the availability of such equipment were more erratic in Jalna, with impressive increases observed in some equipment (syringes and dilators, for example) and declines observed in others (suction machines). In sum, there has been a huge increase in the percentages of PHCs containing all essential equipment in working condition (MVA or EVA suction machines, volsellum, cannulae and autoclave drums); however, the increase is far greater in Aurangabad (from 6\% to $44 \%$ ) than in Jalna (from $11 \%$ to $39 \%)$.
A comparison between non-intervention and intervention facilities in Aurangabad highlights that notwithstanding the fact that intervention facilities were better equipped at baseline than were non-intervention facilities, the availability of functioning essential equipment for the provision of abortion services has increased, on average, far more impressively in these facilities. For example, at baseline, not a single non-intervention PHC and just $13 \%$ of the PHCs selected for intervention contained all of the essential equipment required to provide abortion in working condition; by endline, two-thirds of intervention PHCs, compared to onequarter of non-intervention PHCs contained all such equipment. At the RH level, such distinctions were not observed (Panel B, Table 4.7).

\section{Abortion-related service delivery}

As shown earlier, there has been a considerable increase in the percentage of PHCs and number of RHs providing abortion services in the three years between the baseline and endline surveys, and this increase was far more spectacular in Aurangabad than in Jalna. In this section, we explore service delivery issues in the facilities providing abortion services (Table 4.8).

In all, just one PHC (in Jalna) provided abortion services at the time of the baseline survey, in comparison, 15 of the 45 PHCs in Aurangabad and nine of the 39 PHCs in Jalna were providing abortion services at the time of the endline survey (Panel A, Table 4.8). Further, among PHCs that provided abortion services at the time of the endline survey, all provided first trimester abortions only, and several-seven of the 15 PHCs in Aurangabad and 


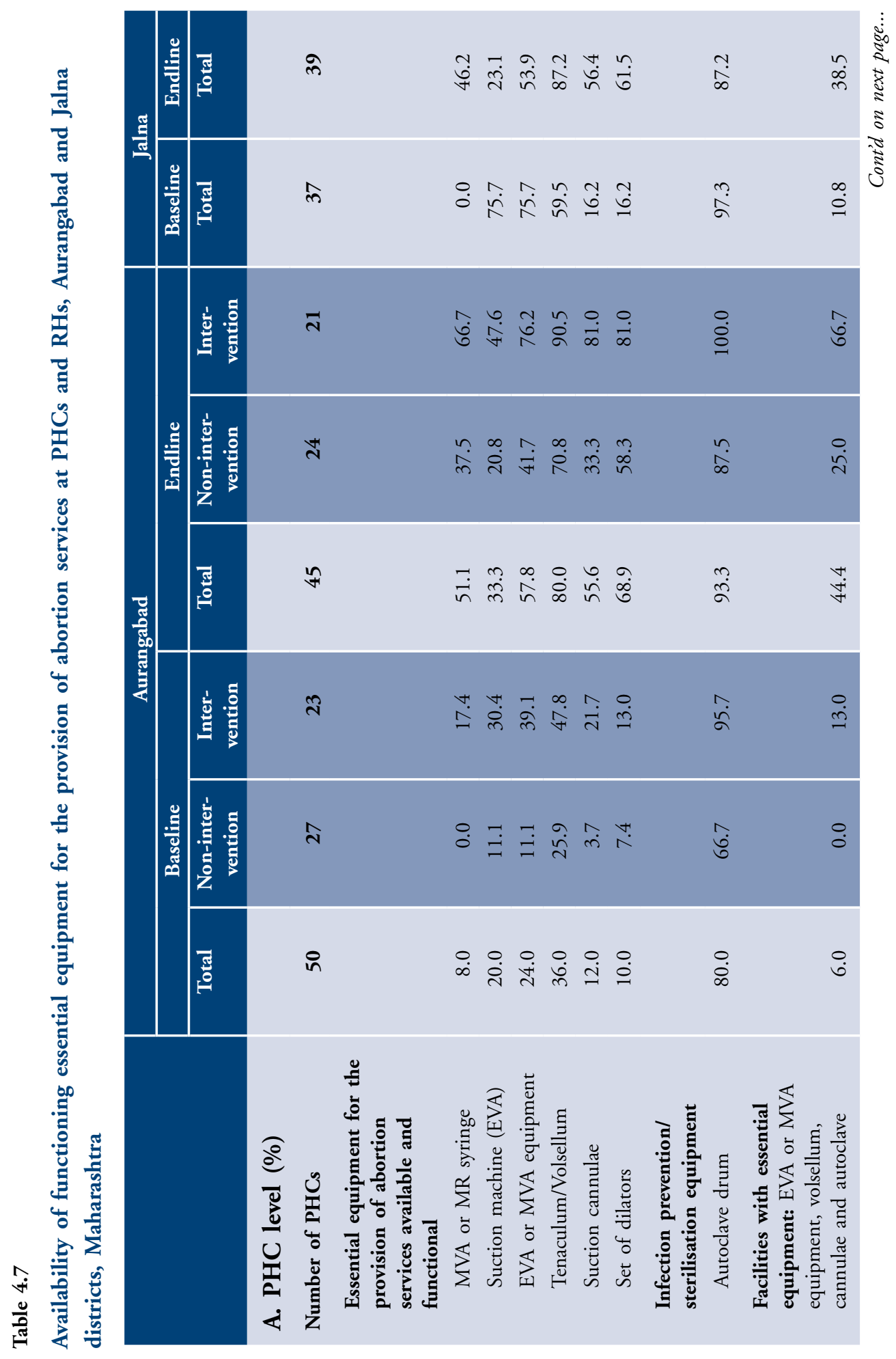




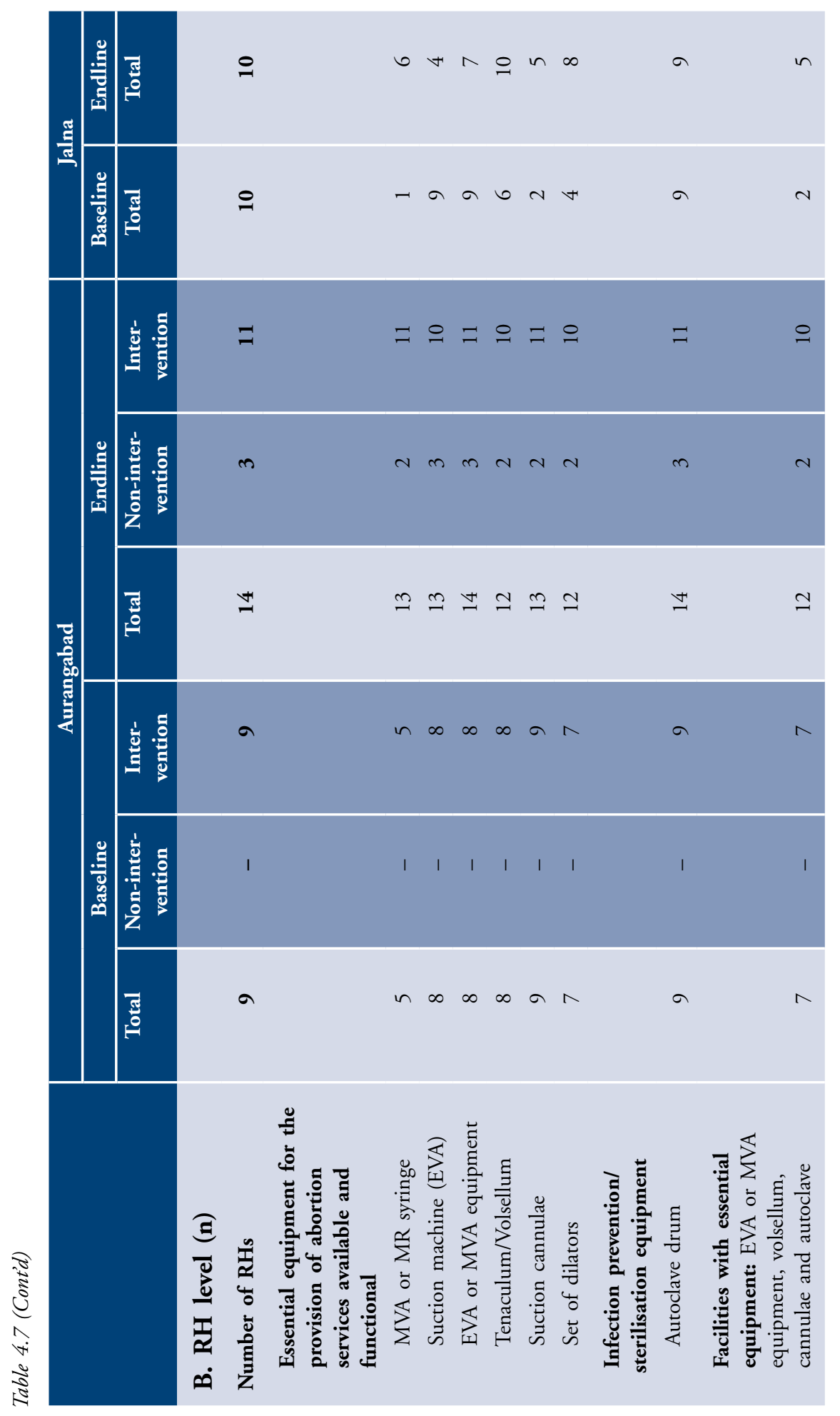


two of the nine in Jalna-did not provide services for incomplete abortion, but rather, referred these cases elsewhere. Just five PHCs in Aurangabad, and eight in Jalna reported that they provided abortion services more than two days a week or on demand.

Again, while the intervention succeeded in ensuring the readiness of PHCs to provide abortion services, the total number of MTPs conducted over the 12-month period preceding the endline survey was moderate, with an average of 15 in PHCs in both Aurangabad and Jalna, and most conducting 50 or fewer abortions. Even so, in the 12 months preceding the interview, two of the 15 PHCs in Aurangabad and none of those in Jalna had conducted more than 50 abortions, and in total, a larger number of abortions had been performed in the PHCs in Aurangabad than those in Jalna (295 versus 148). Notably, moreover, almost all the PHCs were using MVA or MA for first trimester abortions: not a single PHC in Aurangabad and one of the nine PHCs in Jalna reported the use of D\&C for first trimester abortions.

At the time of the endline survey, almost all the PHCs also reported providing post-abortion contraception services. Indeed, all but one PHC (in Jalna) so reported. Also notable was that most PHCs- 13 of the 15 in Aurangabad and six of the nine in Jalna reported providing services to minors and the unmarried. At the same time, almost all facilities-12 of the 15 PHCs in Aurangabad and five of the nine in Jalna-denied services to women if the husband's consent was not available.

On the day of the interview, written guidelines for abortion were available in almost all the PHCs providing abortion: 14 of the 15 PHCs in Aurangabad, and eight of the nine in Jalna. Registers were maintained in all but one facility in Aurangabad, and in six of the nine PHCs in Jalna.

At the RH level too (Panel B, Table 4.8), the number of facilities providing abortion services increased from two to 13 between the baseline and endline surveys in Aurangabad, and from three to four in Jalna. Just three RHs in Aurangabad and two of those in Jalna provided second trimester abortion, and 11 of the 13 RHs in Aurangabad and three of the four in Jalna provided services for incomplete abortion. Here too, however, the number of abortions conducted was moderate: In Aurangabad, just four of the $13 \mathrm{RHs}$ reported conducting 100 or more abortions in the 12 months preceding the interview, compared to two of the four providing abortion services in Jalna. The remaining RHs conducted fewer than 100 abortions in the same 12-month period. At the time of the endline survey, the median number of abortions performed in the year preceding the survey ranged from 68 in Aurangabad to 91 in Jalna, and overall, in the year preceding the endline assessment, a total of 827 abortions had been performed at the RH level in Aurangabad, compared to 859 in Jalna. Notably, this represents a five-fold increase in abortions provided at the RH level in Aurangabad from the year preceding the baseline assessment to the year preceding the endline assessment; the increase in the RHs in Jalna was far less impressive (less than a twofold increase).

Findings also suggested that few RHs provided abortion services more than twice a week or on 
Table 4.8

PHCs and RHs providing abortion, Aurangabad and Jalna districts, Maharashtra

\begin{tabular}{|c|c|c|c|c|}
\hline & \multicolumn{2}{|c|}{ Aurangabad } & \multicolumn{2}{|c|}{ Jalna } \\
\hline & Baseline & Endline & Baseline & Endline \\
\hline \multicolumn{5}{|l|}{ A. PHC level (n) } \\
\hline Number of PHCs providing abortion & $\mathbf{0}$ & 15 & 1 & 9 \\
\hline Services for incomplete abortion available & - & 8 & 0 & 7 \\
\hline \multicolumn{5}{|l|}{$\begin{array}{l}\text { Number of abortions conducted ( } 12 \text { months preceding } \\
\text { the interview })^{1}\end{array}$} \\
\hline 50 or less & - & 13 & 1 & 9 \\
\hline $51-99$ & - & 2 & 0 & 0 \\
\hline 100 or more & - & 0 & 0 & 0 \\
\hline Median number of abortions & - & 15 & - & 15 \\
\hline Total number of abortions conducted & - & 295 & 9 & 148 \\
\hline Provided abortion services $>2$ days a week or on demand & - & 5 & 1 & 8 \\
\hline \multicolumn{5}{|l|}{ Method used for first trimester abortions ${ }^{2}$} \\
\hline MVA/MR & - & 13 & 0 & 7 \\
\hline EVA & - & 0 & 0 & 0 \\
\hline $\mathrm{D} \& \mathrm{C}$ & - & 0 & 1 & 1 \\
\hline MA & - & 5 & 0 & 2 \\
\hline Provided post-abortion contraception & - & 15 & 1 & 8 \\
\hline Abortion provided to minors & - & 13 & 0 & 6 \\
\hline Abortion provided to the unmarried & - & 13 & 0 & 6 \\
\hline Husband's (or guardian's) signature mandatory for abortion & - & 12 & 1 & 5 \\
\hline Written guidelines available at facility & - & 14 & 0 & 8 \\
\hline MTP register maintained at facility & - & 14 & 0 & 6 \\
\hline \multicolumn{5}{|l|}{ B. RH level (n) } \\
\hline Number of RHs providing abortion & 2 & 13 & 3 & 4 \\
\hline Services for second trimester abortion available & 1 & 3 & 2 & 2 \\
\hline Services for incomplete abortion available & 2 & 11 & 2 & 3 \\
\hline \multicolumn{5}{|l|}{$\begin{array}{l}\text { Number of abortions conducted (12 months preceding } \\
\text { the interview) })^{3}\end{array}$} \\
\hline 50 or less & 0 & 6 & 1 & 0 \\
\hline $51-99$ & 1 & 3 & 1 & 2 \\
\hline 100 or more & 1 & 4 & 1 & 2 \\
\hline Median number of abortions & - & 68 & - & 91 \\
\hline Total number of abortions conducted & 160 & 827 & 518 & 859 \\
\hline Provided abortion services $>2$ days a week or on demand & 2 & 3 & 2 & 2 \\
\hline
\end{tabular}

Cont'd on next page... 


\begin{tabular}{|c|c|c|c|c|}
\hline & \multicolumn{2}{|c|}{ Aurangabad } & \multicolumn{2}{|c|}{ Jalna } \\
\hline & Baseline & Endline & Baseline & Endline \\
\hline \multicolumn{5}{|l|}{ Method used for first trimester abortions ${ }^{2}$} \\
\hline MVA/MR syringe & 0 & 10 & 0 & 3 \\
\hline EVA & 1 & 1 & 0 & 1 \\
\hline $\mathrm{D} \& \mathrm{C}$ & 1 & 0 & 1 & 2 \\
\hline MA & 1 & 6 & 0 & 0 \\
\hline Refer elsewhere & 0 & 0 & 2 & 0 \\
\hline Provided post-abortion contraception & 2 & 13 & 3 & 4 \\
\hline Abortion provided to minors & 1 & 12 & 1 & 4 \\
\hline Abortion provided to the unmarried & 1 & 12 & 2 & 4 \\
\hline Husband's (or guardian's) signature mandatory for abortion & 2 & 7 & 2 & 3 \\
\hline Written guidelines available at facility & 2 & 12 & 1 & 4 \\
\hline MTP register maintained at facility & 2 & 13 & 3 & 4 \\
\hline
\end{tabular}

${ }^{1}$ Estimated for PHCs in Jalna district at baseline; obtained from registers for 10 and 3 PHCs in Aurangabad and Jalna, respectively, at endline.

${ }^{2}$ Multiple responses possible.

${ }^{3}$ Obtained from registers for one and 2 RHs in Aurangabad and Jalna, respectively, at baseline; and 9 and 4, respectively, at endline; estimated for others.

demand: two and three in Aurangabad at the time of the baseline and endline surveys, respectively, and two at both times, correspondingly, in Jalna.

The use of $\mathrm{D} \& \mathrm{C}$ for first trimester abortion was rarely reported by any RH. Nevertheless, it is notable that not a single RH in Aurangabad was using D\&C: 11 RHs were using MVA or EVA and six reported using MA for first trimester abortions. In contrast, in Jalna, two of the four RHs providing abortion services continued to use D\&C for first trimester abortions.

All the RHs provided post-abortion contraception and almost all provided abortion services to minors and the unmarried (12 of the
13 RHs in Aurangabad and all four in Jalna). Nevertheless, seven of the 13 RHs in Aurangabad and three of the four in Jalna denied abortion services to women without their husband's written consent.

All the RHs also maintained an MTP register and written guidelines were available in all but one facility (in Aurangabad) at the time of the endline interview.

Differences between intervention and nonintervention facilities in Aurangabad (not presented in table) confirm that a larger number of abortions were reported on average by intervention compared to non-intervention PHCs and RHs, at the time of 
the endline survey. For example, while two of the 12 intervention PHCs had provided 51-99 abortions in the year preceding the endline survey, not a single non-intervention PHC had conducted more than 50 abortions during the same period; likewise, while four of the 11 intervention RHs that were providing abortion at the time of the endline survey reported conducting more than 100 abortions in the year preceding the endline interview, both the nonintervention $\mathrm{RHs}$ reported providing no more than 50 each.

\section{Summary}

Findings highlight that the intervention had a considerable effect on increasing the availability of abortion services in public sector facilities. Indeed, while at baseline, hardly any PHC and just two of the nine RHs in Aurangabad provided abortion services, by endline, one-third of all PHCs and almost all RHs (13 of 14) were doing so. Increases in Jalna were far less spectacular: one-quarter of all PHCs and four of the $10 \mathrm{RHs}$ were providing services at the time of the endline survey.

At the time of the endline survey, MTPcertified medical officers were available in fewer than half of all PHCs and almost all RHs in both districts. However, there was a far more striking increase in the availability of MTP-certified providers at the PHC level in Aurangabad than in Jalna: 41 and 22 percentage points, respectively. Displays of IEC materials on the legality and availability of abortion also increased in both settings, but again, the increase was far more evident in Aurangabad (from 6\% to $69 \%$ of the PHCs, and from three to $12 \mathrm{RHs}$ ) than in Jalna (from 5\% to $49 \%$ of the PHCs and from four to six RHs). Increases in facilities with functioning essential equipment required for the provision of abortion services were also more evident in Aurangabad than in Jalna (48 and 30 percentage points, respectively, at the PHC level; in all $14 \mathrm{RHs}$ in Aurangabad at endline, compared to seven of the 10 $\mathrm{RH}$ in Jalna). Finally, increases in provider awareness about abortion and women's abortion-related rights were also more evident in Aurangabad than Jalna: at the PHC level, awareness of the four key abortionrelated issues increased by 20 percentage points in Aurangabad, compared to no change in Jalna.

While not a single abortion had been conducted at the PHC level in the year preceding the baseline survey in Aurangabad, along with the increase in the number of facilities providing abortion, PHCs in Aurangabad had conducted a total of 295 abortions in the 12 months preceding the endline survey; the corresponding number for Jalna was 148. The total number of abortions conducted over the 12-month period preceding the endline survey averaged 15 in PHCs in both Aurangabad and Jalna.

The caseload over the year was, as expected, higher among RHs. While RHs in Jalna had conducted, in total, more abortions than had those in Aurangabad, the increase in the number of abortions performed in the year preceding the baseline and endline assessments, was far more impressive in Aurangabad (from 160 to 827) than in Jalna (from 518 to 859); over the 12-month period preceding the endline survey, an average of 68 and 91 abortions had been conducted in RHs in Aurangabad and Jalna, respectively. 
Findings also suggest that at the time of the endline assessment, all facilities in Aurangabad had discarded the use of D\&C for first trimester abortions; in contrast, one of the nine PHCs, and two of the four RHs in Jalna continued to use it. Use of medical abortion was also more pronounced in Aurangabad than in Jalna: 11 of the 28 facilities in Aurangabad offered medical abortion, compared to just two of the 13 in Jalna.

The intervention was implemented in slightly less than half of all PHCs in Aurangabad and a comparison of indicators in intervention and non-intervention PHCs in Aurangabad further underscores the role of the intervention. By the time of the endline survey, more than half of the intervention PHCs and all RHs were providing abortion services, compared to just one-quarter of the non-intervention PHCs and two of the three RHs. Likewise, the availability of trained providers, IEC materials and functioning essential equipment for the provision of abortion services were systematically more available in intervention than non-intervention facilities. 


\section{Intervention effects on abortion-related awareness among women}

As noted earlier, the community-based intervention was implemented in the villages served by the PHCs and $\mathrm{RH}$ s in which the facility-level intervention was conducted. This chapter presents findings from the community-based survey relating to women's awareness of various factors relating to abortion and the effect of the intervention on such awareness. It begins by describing the kinds of abortion-related information that respondents had received during the year prior to the interview and the sources of that information, and follows this by a discussion of the levels of awareness of methods of abortion (surgical and medical), the location of facilities providing abortion and the conditions under which abortion may be legally accessed. It then presents findings relating to the effect of the intervention on information obtained and on women's abortionrelated awareness.

Both bivariate and multivariate associations are provided that compare respondents' endline and baseline responses to ascertain the extent of change in the above indicators attributable to exposure to the community intervention. Using pooled data from the baseline and endline surveys, logistic regression models were used to calculate the differencein-difference (DiD) estimate for each outcome indicator. The DiD estimate enables us to assess the net effect of exposure to the intervention on various outcome indicators after controlling for potentially confounding factors. Explanatory variables include a dummy variable indicating the time of the survey (baseline $=0$ and endline $=1$ ), variables indicating women's exposure to the intervention (not exposed=0 and exposed=1), a dummy variable for exposure to the intervention in the endline survey (the DiD estimate), and socio-demographic characteristics of women such as age, education, children ever born, household economic status and previous experience of abortion. In the regression models, respondents from Jalna were compared with those from Aurangabad after controlling for all the above confounding factors. The DiD estimates, shown as odds ratios, enable us to derive the impact of the district-level model intervention.

\section{Abortion-related information: Sources and messages}

In order to assess the reach of the communication strategy, all respondents were asked whether they had received any information about abortion in the year preceding the interview, and more specifically, the sources of such information. Findings, presented in Table 5.1, highlight that significantly more women had received information about abortion in the year preceding the endline survey than had those in the year preceding the baseline survey, and that the increase was more pronounced in Aurangabad than in Jalna: from $20 \%$ to $48 \%$ in Aurangabad, and from $18 \%$ to $37 \%$ in Jalna (Panel A). Key sources of information also varied over time. For example, percentages of women obtaining information from interpersonal contacts (IPC) and group meetings 


\section{Table 5.1}

Effects of the intervention on information received by women on abortion, Aurangabad and Jalna districts, Maharashtra

\begin{tabular}{|c|c|c|c|c|}
\hline & \multicolumn{2}{|c|}{ Aurangabad } & \multicolumn{2}{|c|}{ Jalna } \\
\hline & Baseline & Endline & Baseline & Endline \\
\hline Number of women & 1,308 & 1,013 & 1,339 & 1,017 \\
\hline \multicolumn{5}{|l|}{ A. Bivariate results (\%) } \\
\hline \multicolumn{5}{|l|}{ Formal sources of information about abortion } \\
\hline Received information from any source & 19.8 & $48.1^{* * *}$ & 17.5 & $36.7^{* * *}$ \\
\hline \multicolumn{5}{|l|}{ Received information from: ${ }^{1}$} \\
\hline $\begin{array}{l}\text { Mass media (TV, radio, newspaper, magazine, poster/bill } \\
\text { board etc.) }\end{array}$ & 6.0 & $35.7^{* * *}$ & 5.6 & $30.2^{* * *}$ \\
\hline $\mathrm{IPC}^{2}$, group meetings, wall signs, street plays & 15.4 & $29.8^{* * *}$ & 13.0 & $15.9^{*}$ \\
\hline $\mathrm{IPC}^{2}$ & 9.5 & 9.1 & 11.1 & $6.2^{* * *}$ \\
\hline Group meetings & 6.0 & 6.4 & 1.9 & 1.2 \\
\hline Wall sign in the village & - & 19.4 & - & 10.2 \\
\hline Street play & - & 5.4 & - & 0.5 \\
\hline \multicolumn{5}{|l|}{ Informal sources of information about abortion } \\
\hline Discussed/shared information about abortion with family or friends & 20.5 & $38.9^{* * *}$ & 33.1 & $50.8^{* * *}$ \\
\hline \multicolumn{5}{|l|}{ B. Multivariate results (odds ratio, DiD estimate) ${ }^{3}$} \\
\hline Received information from at least one formal source ${ }^{4}$ & \multirow{2}{*}{\multicolumn{4}{|c|}{$1.31(1.00-1.72)$}} \\
\hline $\begin{array}{l}\text { Received information from } \mathrm{IPC}^{2} \text {, group meetings, wall signs or } \\
\text { street plays }{ }^{4}\end{array}$ & & & & \\
\hline Received information from/discussed with informal network ${ }^{4}$ & \multicolumn{4}{|c|}{$1.12(0.87-1.44)$} \\
\hline
\end{tabular}

${ }^{*} p<=0.05 ;{ }^{* *} p<=0.01 ;{ }^{* * *} p<=0.001$

${ }^{1}$ Multiple responses possible.

${ }^{2}$ Includes health care providers from public or private sector facilities.

${ }^{3}$ Odds ratios greater than 1.0 imply a positive net effect.

${ }^{4}$ Controlling age, years of education attained, total number of children ever born and standard of living index.

(both those conducted as part of the intervention and those conducted by others in the public, NGO or private sectors) did not change in Aurangabad, and fell in Jalna. In contrast, two sources of information emphasised by the intervention-wall signs and street plays-were not evident at baseline in both districts but were reported by $19 \%$ and
$5 \%$ of the women, respectively in Aurangabad; and $10 \%$ and $1 \%$, respectively, in Jalna (perhaps the result of women from Jalna visiting contiguous villages in neighbouring Aurangabad). The leading source of information for women in both districts was, however, the mass media, increasing significantly in both settings-from $6 \%$ to $36 \%$ in 
Aurangabad and from $6 \%$ to $30 \%$ in Jalna. Aside from the more formal sources of information, many women reported discussing abortion in informal networks, that is, with their friends and relatives, and proportions doing so increased substantially in both districts; they almost doubled in Aurangabad (from $21 \%$ to $39 \%$ ) and increased somewhat less impressively in Jalna (from 33\% to 51\%).

To assess the net effect of exposure to the intervention on women's access to information about abortion and discussion of abortion in informal networks in the year preceding the interview, logistic regression analyses were conducted to obtain the $\mathrm{DiD}$ estimate, after controlling for potentially confounding factors. The findings, presented in Table 5.1, Panel $\mathrm{B}$, suggest that differences observed in the bivariate comparisons with regard to access to information from interpersonal contacts, group meetings, wall signs and/or street plays continued to be significant after controlling for potentially confounding factors. In contrast, when exposure to all sources of information including the mass media is considered and when discussion in informal networks is considered, the effect of the intervention is not observed.

Findings also suggest that at the time of the endline survey, the messages received by respondents varied considerably by source of message and district of residence (Table 5.2). For example, messages obtained from the mass media were focused largely on sex-selective abortion and the prescriptions of the Pre-conception and Pre-natal Diagnostic Techniques (PCPNDT) Act, with $70-73 \%$ of the women who obtained one or more messages from the media recalling such information; on almost all messages received from the media, inter-district variation was insignificant. In contrast, among women who had received abortion-related messages from interpersonal contacts, group meetings, wall signs and street plays, inter-district differences were significant. For example, women in Aurangabad who were exposed to interpersonal contacts, group meetings, wall signs and street plays were significantly more likely than those in Jalna to report having been informed about the legality of abortion, the fact that abortion services are available at public sector facilities and the fact that non-surgical options for abortion are available; they were, in contrast, less likely to report negative messages about abortion.

\section{Awareness of abortion methods}

Table 5.3 presents the endline and baseline responses of respondents from the intervention and control districts to questions relating to awareness of abortion methods. Findings presented in Panel A of the table indicate that while the large majority of women were aware that a pregnancy can be terminated, awareness of both surgical and medical methods of abortion (surgical or medical) increased significantly in Aurangabad but actually declined in Jalna. For example, awareness of surgical abortion increased from $73 \%$ to $84 \%$ in Aurangabad and fell slightly from $83 \%$ to $78 \%$ in Jalna. Likewise, awareness of medical abortion increased significantly in Aurangabad (from $44 \%$ to $52 \%$ ); in contrast, awareness of medical abortion fell in Jalna (from $59 \%$ to $45 \%$ ). We note that at baseline we did not probe the exact nature of the oral medication, and since there are a variety of Ayurvedic and other preparations available that are believed to induce 


\section{Table 5.2}

Messages received by women who reported receiving information on abortion in the year preceding the endline interview by source of message, Aurangabad and Jalna districts, Maharashtra

\begin{tabular}{|c|c|c|c|c|c|c|}
\hline & \multicolumn{2}{|c|}{ Any source } & \multicolumn{2}{|c|}{ Mass media } & \multicolumn{2}{|c|}{$\begin{array}{l}\text { IPC, group meetings, wall } \\
\text { signs or street plays }\end{array}$} \\
\hline & Aurangabad & Jalna & Aurangabad & Jalna & Aurangabad & Jalna \\
\hline Messages (\%) & & & & & & \\
\hline $\begin{array}{l}\text { Abortion is legal, can be conducted } \\
\text { up to } 20 \text { weeks, in case of } \\
\text { contraceptive failure, in case of } \\
\text { rape, if the woman's health is in } \\
\text { danger, or if there is a serious } \\
\text { defect in the baby }\end{array}$ & 19.1 & $8.6^{* * *}$ & 11.6 & $7.2^{*}$ & 20.9 & $8.6^{* * *}$ \\
\hline Early abortion is safe for a woman & 19.5 & $12.9^{* *}$ & 8.8 & 8.8 & 22.5 & 16.1 \\
\hline $\begin{array}{l}\text { Abortion services are available at } \\
\text { public sector facilities }\end{array}$ & 24.0 & $16.4^{* *}$ & 16.6 & 13.4 & 22.5 & $13.6^{*}$ \\
\hline $\begin{array}{l}\text { Unwanted pregnancy can be } \\
\text { prevented by regular use of } \\
\text { contraception }\end{array}$ & 18.1 & 14.8 & 16.6 & 11.7 & 12.9 & 13.6 \\
\hline $\begin{array}{l}\text { Sex-selective abortion is illegal in } \\
\text { India }\end{array}$ & 63.5 & 67.3 & 69.6 & 72.6 & 36.1 & 40.1 \\
\hline $\begin{array}{l}\text { Pills are available that can terminate } \\
\text { a pregnancy }\end{array}$ & 21.8 & $15.6^{*}$ & 19.9 & 17.6 & 14.9 & $2.5^{* * *}$ \\
\hline Abortion is a sin/wrong/illegal & 2.1 & $8.3^{*}$ & 1.9 & $5.9^{*}$ & 1.3 & $9.3^{* *}$ \\
\hline $\begin{array}{l}\text { Number of women exposed to } \\
\text { messages }\end{array}$ & 487 & 373 & 362 & 307 & 302 & 162 \\
\hline
\end{tabular}

abortion, it is very unlikely that all of these women were reporting awareness of the mifepristonemisoprostol combination; in contrast, at endline, women who reported awareness of oral preparations were probed to ensure awareness of the mifepristonemisoprostol combination. Hence, the decline in awareness of medical abortion in Jalna may have resulted from more accurate reporting of awareness at endline. Nevertheless, this makes the increase observed in Aurangabad all the more impressive.
The results of the logistic regression analysis, using the DiD model, are presented in Panel B, Table 5.3. Findings show that after controlling for potentially confounding factors and time, the net effect of the intervention on awareness of abortion methods - any method, as well as surgical and medical methods individually—was positive and significant. 


\section{Table 5.3}

Effects of the intervention on women's awareness of abortion methods, Aurangabad and Jalna districts, Maharashtra

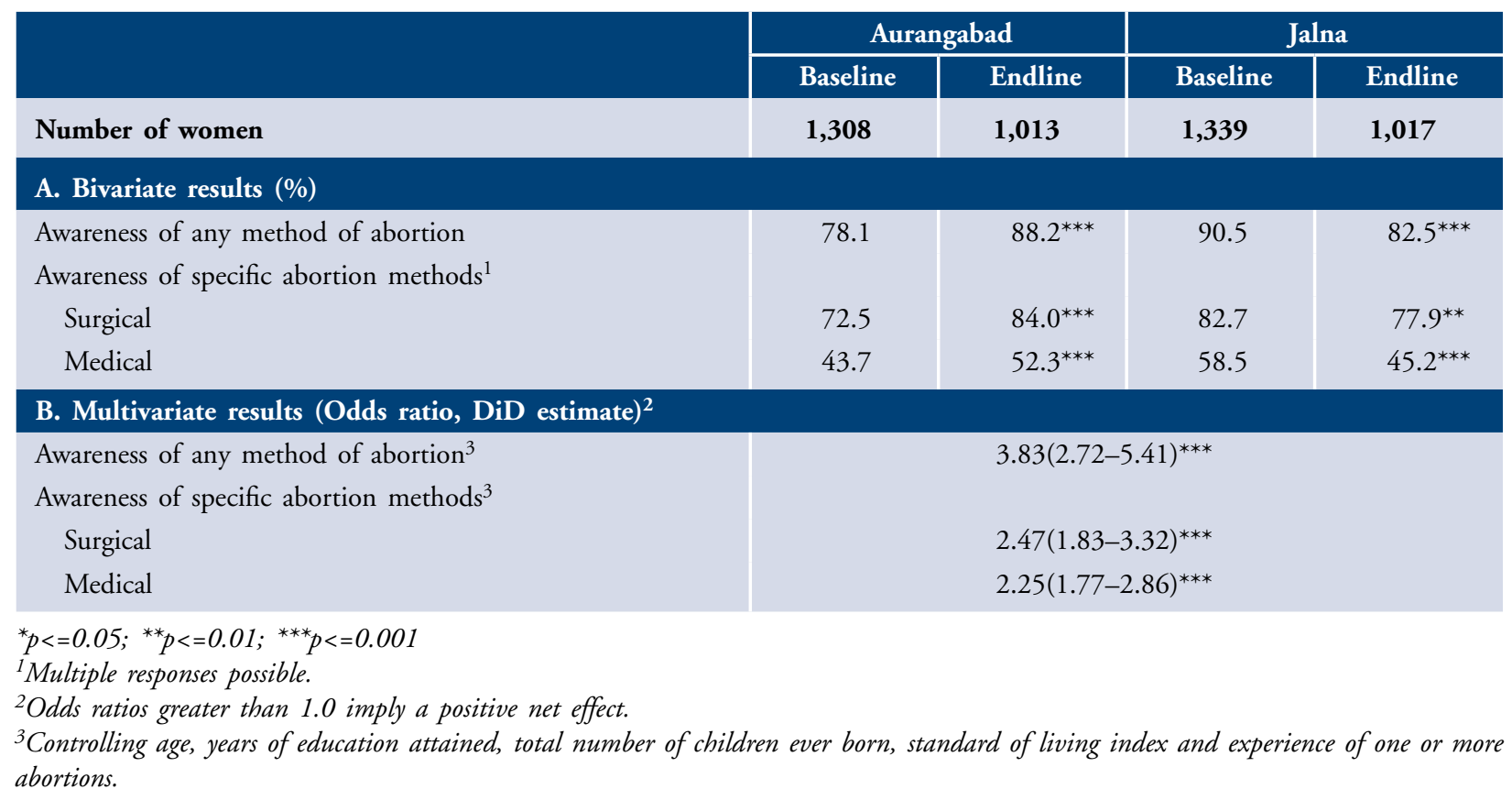

\section{Awareness of facilities providing abortion services}

The community-level intervention sought to inform women in Aurangabad about the availability of abortion services in public sector facilities, and findings suggest that the intervention did indeed raise their awareness of such facilities (Table 5.4). Findings (in Panel A of the table), show that awareness that abortion is provided at public sector facilities, and notably at RHs and PHCs, did indeed increase significantly in Aurangabad, and to a lesser extent in Jalna. For example, awareness that abortion is performed in any public sector facility increased from $39 \%$ to $70 \%$ in Aurangabad, and from $36 \%$ to $52 \%$ in Jalna; that it is performed in District Hospitals increased from $29 \%$ to $54 \%$ in Aurangabad, compared to from $28 \%$ to $38 \%$ in Jalna; and that it is performed in RHs and PHCs from $22 \%$ to $62 \%$ in Aurangabad, compared to an increase from $17 \%$ to $45 \%$ in Jalna. At the same time, awareness that chemists provide drugs that can terminate a pregnancy increased significantly in Aurangabad (19\% to $27 \%$ ) but remained unchanged in Jalna.

Findings clearly show that the intervention had a positive net effect on respondents' awareness of public sector facilities for abortion. Indeed, the net effect of the intervention was positive and significant with regard to awareness that abortion is available in any public sector facility (District Hospital, RH and/ 
or PHC), as well as, more specifically, with regard to women's awareness that abortion is available in such lower level facilities as PHCs and RHs (Panel B, Table 5.4).

\section{Perceptions about community access to abortion}

Women were also asked about facilities from which or providers from whom women in their community

Table 5.4

Effects of the intervention on women's awareness of facilities providing abortion, Aurangabad and Jalna districts, Maharashtra

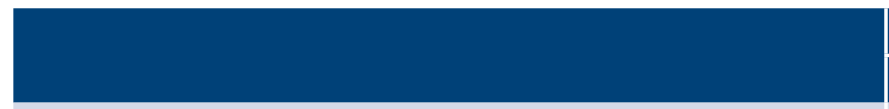

Number of women

A. Bivariate results (\%)

Awareness of public or private sector facilities/providers of abortion services

Any public sector facility ${ }^{1}$

District Hospital

PHC or RH

Private sector facility/doctor

Awareness of other providers of abortion services ${ }^{1}$

ANM/Nurse

Chemist

Awareness only of likely unsafe sources of abortion

\begin{tabular}{|c|c|c|c|}
\multicolumn{2}{|c|}{ Aurangabad } & \multicolumn{2}{c|}{ Jalna } \\
\hline Baseline & Endline & Baseline & Endline \\
\hline 1,308 & 1,013 & 1,339 & 1,017 \\
\hline
\end{tabular}

B. Multivariate results (Odds ratio, DiD estimate) ${ }^{2}$

Awareness of abortion facilities/providers ${ }^{3}$

Any public or private facilities

Any public sector facility

$\mathrm{PHC}$ or $\mathrm{RH}$

Private sector facilities

$$
\begin{aligned}
& 1.53(1.15-2.03)^{* *} \\
& 1.76(1.38-2.24)^{* * *} \\
& 1.41(1.08-1.84)^{*} \\
& 1.07(0.84-1.37)
\end{aligned}
$$

${ }^{*} p<=0.05 ;{ }^{* *} p<=0.01 ;{ }^{* * *} p<=0.001$

${ }^{1}$ Multiple responses possible.

${ }^{2}$ Odds ratios greater than 1.0 imply a positive net effect.

${ }^{3}$ Controlling age, years of education attained, total number of children ever born, standard of living index and experience of one or more abortions. 
were likely to seek abortion services. Findings, reported in Table 5.5, mirror those reported above. The majority of women in both districts were most likely to report that women would seek abortion services from a private sector physician and proportions so reporting remained unchanged from baseline to endline (58\% to $62 \%$ in Aurangabad, $68 \%$ to $69 \%$ in Jalna). Notably, despite the considerable awareness that nurses, ANMs, chemists and others provided abortion services, few women in both settings reported that women would seek abortion services from such providers-just $6-8 \%$ at baseline, and 3-7\% at endline in Aurangabad and Jalna, respectively.

Multivariate findings presented in Table 5.5 confirm, correspondingly, that after controlling for potentially confounding factors and time, the net effect of the intervention on perceptions that women in the community would seek abortion from a public sector facility was positive and significant. In contrast, the intervention did not have a significant effect on perceptions about women's access to abortion from unqualified providers.

Table 5.5

Effects of the intervention on women's perceptions about community access to abortion, Aurangabad and Jalna districts, Maharashtra

\begin{tabular}{|c|c|c|c|c|}
\hline & \multicolumn{2}{|c|}{ Aurangabad } & \multicolumn{2}{|c|}{ Jalna } \\
\hline & Baseline & Endline & Baseline & Endline \\
\hline Number of women & 1,308 & 1,013 & 1,339 & 1,017 \\
\hline \multicolumn{5}{|l|}{ A. Bivariate results (\%) } \\
\hline Any public sector facility ${ }^{1}$ & 40.2 & $52.8^{* * *}$ & 37.3 & 33.9 \\
\hline District Hospital & 30.9 & $37.3^{* *}$ & 31.1 & $23.2^{* * *}$ \\
\hline $\mathrm{PHC}$ or $\mathrm{RH}$ & 17.7 & $25.0^{* * *}$ & 13.6 & $17.9^{* *}$ \\
\hline Private sector facility/doctor & 58.0 & 61.5 & 68.0 & 69.0 \\
\hline Other providers ${ }^{1}$ & 5.7 & $3.3^{* *}$ & 8.4 & 6.9 \\
\hline ANM/Nurse & 2.4 & 2.5 & 5.3 & 6.6 \\
\hline Chemist & 0.8 & 0.6 & 3.0 & $0.3^{* * *}$ \\
\hline Dai/TBA ${ }^{2} /$ herbalist/other traditional practitioner & 2.1 & $0.2^{* * *}$ & 1.0 & $0.0^{* *}$ \\
\hline Don't know & 20.9 & $14.9^{* * *}$ & 15.0 & 17.5 \\
\hline \multicolumn{5}{|l|}{ B. Multivariate results (Odds ratio, DiD estimate) } \\
\hline Access abortion from public sector ${ }^{3,4}$ & \multicolumn{4}{|c|}{$1.90(1.50-2.41)^{* * *}$} \\
\hline Access abortion from unsafe providers $\mathrm{s}^{4,5}$ & \multicolumn{4}{|c|}{$0.69(0.41-1.17)$} \\
\hline \multicolumn{5}{|c|}{$\begin{array}{l}{ }^{*} p<=0.05 ;{ }^{* *} p<=0.01 ;{ }^{* * *} p<=0.001 \\
{ }^{1} \text { Multiple responses possible. } \\
{ }^{2} \text { Dai or TBA: traditional birth attendant. } \\
{ }^{3} \text { Odds ratio greater than } 1.0 \text { implies a positive net effect. } \\
{ }^{4} \text { Controlling: age, years of education attained, total number of children ever born, standard of living index and experience of one or more } \\
\text { abortions. } \\
{ }^{5} \text { Odds ratio less than } 1.0 \text { implies a positive net effect. }\end{array}$} \\
\hline
\end{tabular}




\section{Awareness of legal issues related to abortion}

Given the lack of awareness about the conditions under which abortion is legal in India, an important component of the community-level intervention was to raise awareness and rectify misconceptions about the conditions under which abortion is legal. Questions regarding awareness of the legality of abortion probed whether women were aware that abortion is legal in a host of situations, as described in Table 5.6. Findings confirm that awareness that abortion is legal in at least one situation has increased significantly in Aurangabad (from $72 \%$ to $85 \%)$ compared to a mild decline in Jalna $(84 \%$ to $80 \%)$. At the same time, misperceptions about conditions in which abortion is legal have declined significantly in both settings, from $73 \%$ to $62 \%$ in Aurangabad, and from $73 \%$ to $65 \%$ in Jalna. What is disturbing, however, is that about half of all women in Aurangabad and two-fifths of those in Jalna reported that they were unsure about the legality of at least one condition about which questions were posed, and that there was little change in these percentages over time.

Misperceptions regarding individual conditions under which abortion is legal, however, remain quite widespread, but even so, fell uniformly in Aurangabad and less consistently in Jalna. For example, at baseline, about half of all women in both districts believed that an unmarried woman and a woman whose pregnancy results from contraceptive failure cannot legally access abortion; while this percentage declined narrowly in Jalna (from 47-50 to 44-50), it declined significantly in Aurangabad (from 48-52 to 38), at endline. At the same time, both districts recorded huge declines in the percentages considering it illegal for a woman whose health is endangered or whose foetus faces risks to undergo an abortion. The two issues about which misconceptions were rarely held at endline were that it is illegal for a woman who is more than 20 weeks pregnant to undergo abortion $(6-7 \%)$ and that sexselective abortion is illegal (4-5\%).

Even so, the large majority of women continue to believe that a woman undergoing abortion needs her husband's consent. In both districts, percentages reporting this misperception declined between the time of the baseline and endline surveys: from 87 to 77 in Aurangabad and from 89 to 75 in Jalna. It is notable that even at endline, just $9-10 \%$ of the women recognised that an adult woman is legally entitled to undergo abortion without the consent of her husband or guardian, and 14-15\% were unsure about this (not shown in table).

The results of the logistic regression analysis, using the DiD model to compare changes in awareness of the legality of abortion between baseline and endline respondents in Aurangabad and Jalna are presented in Table 5.7. Findings suggest that the net effect of the intervention was positive and significant with regard to awareness of at least one condition under which abortion is legal. Conversely, the net effect of the intervention on misperceptions of various conditions under which abortion is legal was negative and significant; nonetheless, the effect of the intervention was not evident with regard to reducing misperceptions of two issues-that abortion is illegal for women with gestational ages exceeding 20 weeks 


\section{Table 5.6}

Percentage of women by misperceptions held about the legality of abortion and awareness of at least one situation in which abortion is legal, Aurangabad and Jalna districts, Maharashtra

\begin{tabular}{|c|c|c|c|c|}
\hline & \multicolumn{2}{|c|}{ Aurangabad } & \multicolumn{2}{|c|}{ Jalna } \\
\hline & Baseline & Endline & Baseline & Endline \\
\hline Number of women & 1,308 & 1,013 & 1,339 & 1,017 \\
\hline \multicolumn{5}{|l|}{ Awareness of legality of abortion $(\%)^{1}$} \\
\hline Aware that abortion is legal in at least one condition & 71.9 & $85.2^{* * *}$ & 83.6 & $79.9^{*}$ \\
\hline $\begin{array}{l}\text { Is unsure about the legality of abortion in at least one } \\
\text { condition }\end{array}$ & 48.2 & 50.1 & 43.8 & 42.0 \\
\hline $\begin{array}{l}\text { Misperceives that abortion is illegal in at least one valid } \\
\text { condition }\end{array}$ & 73.4 & $62.1^{* * *}$ & 72.9 & $64.9^{* * *}$ \\
\hline \multicolumn{5}{|l|}{ Misperceptions held: $\%$ women reported that it is illegal } \\
\hline For a married woman to access abortion & NA & 54.4 & NA & 64.8 \\
\hline For an unmarried woman to access abortion & 47.8 & $37.6^{* * *}$ & 49.8 & 50.2 \\
\hline $\begin{array}{l}\text { For a woman whose pregnancy results from contraceptive failure } \\
\text { ("accidentally") to access abortion }\end{array}$ & 51.6 & $38.1^{* * *}$ & 47.4 & 44.3 \\
\hline $\begin{array}{l}\text { For a woman whose pregnancy has resulted from rape to access } \\
\text { abortion }\end{array}$ & 41.4 & $19.8^{* * *}$ & 39.0 & 37.4 \\
\hline $\begin{array}{l}\text { For a woman whose health is endangered by the pregnancy to } \\
\text { access abortion }\end{array}$ & 32.6 & $10.7^{* * *}$ & 25.9 & $18.2^{* * *}$ \\
\hline $\begin{array}{l}\text { If there is a strong chance of foetal malformation, for a woman } \\
\text { to access abortion }\end{array}$ & 37.8 & $13.2^{* * *}$ & 29.4 & $17.3^{* * *}$ \\
\hline $\begin{array}{l}\text { For a woman who is more than } 20 \text { weeks pregnant to access } \\
\text { abortion }\end{array}$ & 12.3 & $6.7^{* * *}$ & 8.9 & $5.9^{* *}$ \\
\hline If the foetus is female & NA & 3.7 & NA & 4.6 \\
\hline Women aware about consent procedures (\%) & & & & \\
\hline $\begin{array}{l}\text { Misperceiving that a woman undergoing abortion needs her } \\
\text { husband's consent }\end{array}$ & 87.4 & $76.7^{* * *}$ & 89.2 & $75.0^{* * *}$ \\
\hline
\end{tabular}

${ }^{*} p<=0.05 ;{ }^{* *} p<=0.01 ;{ }^{* * *} p<=0.001$

${ }^{1}$ Excludes awareness of two conditions, for a married woman to access abortion and if the foetus is a female. 


\section{Table 5.7}

Effects of the intervention on women's awareness of the legality of abortion: Summary of logistic regression results using the DiD model, Aurangabad and Jalna districts, Maharashtra

\begin{tabular}{|c|c|}
\hline \multirow[t]{2}{*}{ Dependent variables } & Odds ratio \\
\hline & Effect of intervention (DiD estimate) \\
\hline \multicolumn{2}{|l|}{ Legality of abortion ${ }^{1,2}$} \\
\hline Knows at least one condition in which abortion is legal & $2.62(1.93-3.56)^{* * *}$ \\
\hline \multicolumn{2}{|l|}{ Holds the following misperceptions: ${ }^{2,3}$} \\
\hline It is illegal for an unmarried woman to access abortion & $0.67(0.53-0.85)^{* *}$ \\
\hline $\begin{array}{l}\text { It is illegal for a woman whose pregnancy results from contraceptive failure } \\
\text { ("accidentally") to access abortion }\end{array}$ & $0.68(0.54-0.87)^{* *}$ \\
\hline $\begin{array}{l}\text { It is illegal for a woman whose pregnancy has resulted from rape to access } \\
\text { abortion }\end{array}$ & $0.39(0.30-0.50)^{* * *}$ \\
\hline $\begin{array}{l}\text { It is illegal for a woman whose health is endangered by the pregnancy to access } \\
\text { abortion }\end{array}$ & $0.42(0.31-0.57)^{* * *}$ \\
\hline $\begin{array}{l}\text { If there is a strong chance of foetal malformation, it is illegal for a woman to } \\
\text { access abortion }\end{array}$ & $0.54(0.40-0.73)^{* * *}$ \\
\hline It is legal for a woman who is more than 20 weeks pregnant to access abortion & $0.75(0.48-1.16)$ \\
\hline A woman undergoing abortion needs her husband's consent & $1.23(0.90-1.68)$ \\
\hline
\end{tabular}

and that the husband's consent is not required for women undergoing abortion.

\section{Summary}

Findings suggest that at the time of the endline survey, women in Aurangabad were considerably more likely than those in Jalna to have received messages through interpersonal contacts, group meetings, wall signs and street plays, concerning the legality of abortion, its availability in public sector facilities and the fact that pregnancy can be terminated using oral medication. In addition, findings show that there have been significant improvements in awareness, notably in the intervention district, between the time of the baseline and endline surveys. For example, awareness of medical abortion increased significantly (by 8 percentage points) in Aurangabad, but fell by 14 percentage points in Jalna. Awareness that abortion is available in public sector facilities also increased significantly (by 10 percentage points) in Aurangabad, but remained unchanged in Jalna. Awareness that abortion is available at the PHC/ RH level increased by 41 percentage points in Aurangabad, compared to 29 percentage points in Jalna. Awareness of at least one condition in which 
abortion is legally available increased significantly (by 13 percentage points) in Aurangabad, but fell (by 4 percentage points) in Jalna. At the same time, misperceptions that abortion is illegal in at least one valid condition fell in both settings - by 11 percentage points in Aurangabad and 8 percentage points in Jalna.

Findings highlight, finally, that the intervention had a significant positive net effect on most indicators reflecting women's awareness of abortion- related matters: awareness of surgical and medical abortion, and awareness that abortion is available in public sector facilities in general, and PHCs and RHs in particular. Moreover, findings confirm that the intervention had a significant negative net effect on misperceptions held about conditions under which abortion is legal. Indeed, the net effect of the intervention on reducing misperceptions was significant and negative in five of the seven conditions probed. 


\section{CHAPTER 6}

\section{Experiences of women who underwent abortion}

As mentioned earlier, the longer term objectives of the district-level CAC model were to increase women's access to safe abortions from the public sector and reduce unsafe aspects of abortion, including delayed abortion and resort to multiple providers. This chapter explores the progress made in the short period under observation in changing these practices, among women whose abortion had taken place in the three years preceding the base- and endline interviews. We note that the numbers of women who underwent abortion in the three years preceding each survey were relatively small, making analysis somewhat difficult; findings must be interpreted as illustrative and not conclusive.

\section{Prevalence of abortion: Lifetime and recent}

Table 6.1 shows that $5-7 \%$ of women in both Aurangabad and Jalna had undergone an abortion at least once in the three years preceding the baseline and endline interviews. District-wise patterns suggest very small changes in percentages who had experienced an abortion: a small increase in Aurangabad (from 5 to 7), and an equally small decline in Jalna (from 6 to 5). The abortion ratio, that is, abortions per 100 live births, displayed a similar trend; it increased in Aurangabad (from 12 to 16 in the three years prior to the interview) and declined modestly in Jalna (from 14 to 11 ). We note that the increase observed in Aurangabad may be the result of more accurate reporting, given the emphasis on the acceptability of abortions transmitted by the intervention.

\section{Abortion-related experiences}

We focus in this section on such abortion-related experiences of women as the abortion provider and facility, and the method of abortion used. It also

\section{Table 6.1}

Prevalence of abortion in the three years preceding the interview, Aurangabad and Jalna districts, Maharashtra

\begin{tabular}{|c|c|c|c|c|}
\hline & \multicolumn{2}{|c|}{ Aurangabad } & \multicolumn{2}{|c|}{ Jalna } \\
\hline & Baseline & Endline & Baseline & Endline \\
\hline Number of women & 1,308 & 1,013 & 1,339 & 1,017 \\
\hline \multicolumn{5}{|c|}{$\begin{array}{l}\text { Prevalence of abortion in the three years preceding the } \\
\text { interview }\end{array}$} \\
\hline Experienced abortion (\%) & 4.9 & 6.8 & 5.5 & 4.5 \\
\hline Abortion ratio ${ }^{1}$ & 12.3 & 16.2 & 13.8 & 10.6 \\
\hline
\end{tabular}

${ }^{*} p<=0.05 ;{ }^{* *} p<=0.01 ;{ }^{* * *} p<=0.001$

${ }^{1}$ Abortions per 100 live births. 
assesses the extent to which practices such as second trimester and repeat abortions prevailed.

As many as $94-96 \%$ of women who had experienced a recent abortion in both districts reported that their abortion had been conducted by an allopathic doctor (Table 6.2). Overwhelmingly, the private sector was preferred, notwithstanding our earlier finding of the large increase in abortions conducted in PHCs and RHs. In Aurangabad, however, there was a small increase in the use of public sector facilities by women (from 6\% to $12 \%$ ) compared to a decline in Jalna (from $10 \%$ to $4 \%$ ). More specifically, there was a slight increase in the percentages of women in Aurangabad reporting that their abortion had taken place in a PHC or RH (from 2 to 9); no such indication was evident in Jalna. Uncertified providers were cited, moreover by $6 \%$ and $4 \%$ of women in Aurangabad and Jalna, respectively, at the time of the endline survey, mostly chemists from whom abortion-inducing drugs were purchased (4\% in both settings).

With regard to the method used for pregnancy termination, women were asked whether their abortion had been terminated using surgical or medical methods. In order to distinguish between MVA and D\&C, we asked women who reported surgical abortion whether they had been made unconscious (given general anaesthesia for the surgical procedure) or not (MVA). We did not probe the nature of the oral medication taken at baseline and hence cannot confirm whether this was indeed the mifepristone-misoprostol combination or one of the many Ayurvedic and other preparations available.
Findings indicated a significant shift away from D\&C towards MVA and MA in both settings (Table 6.2). Indeed, while at baseline, about three in five abortions had been conducted using D\&C (surgery with general anaesthesia), by the time of the endline, this proportion had fallen significantly in both districts- to around one in three in Aurangabad and two in five in Jalna. At the same time, there were increases in the percentages reporting MVA (surgery without general anaesthesia, using a syringe or 'pichkari) and medical abortion (abortion using pills); while the use of MVA increased from 22\% to $29 \%$ in Aurangabad, and more so in Jalna (from $20 \%$ to $28 \%$ ); the use of medical abortion increased dramatically in both Aurangabad (from 16\% to $38 \%$ ) and Jalna (from $7 \%$ to $33 \%$ ).

\section{Experiences of second trimester and repeat abortions}

As far as the timing of abortion is concerned, the large majority of women who underwent an abortion in the three years preceding the interview reported terminating their pregnancy in the first trimester. However, as shown in Table 6.3, a large minority of these women reported a second trimester abortion, and the proportions of such women remained virtually unchanged in both districts across the baseand end-line surveys, and were somewhat lower in Aurangabad (19\%) than in Jalna (24-26\%).

Also evident from Table 6.3 is the finding that a small percentage of women whose most recent abortion had taken place in the three years prior to the interview reported an additional abortion in the 


\section{Table 6.2}

Percentage of women by facility/individual who conducted the abortion and abortion method used, among women who underwent abortion in the three years preceding the interview, Aurangabad and Jalna districts, Maharashtra

\begin{tabular}{|c|c|c|c|c|}
\hline & \multicolumn{2}{|c|}{ Aurangabad } & \multicolumn{2}{|c|}{ Jalna } \\
\hline & Baseline & Endline & Baseline & Endline \\
\hline $\begin{array}{l}\text { Number of women who underwent an abortion in the three } \\
\text { years preceding the interview }\end{array}$ & 64 & 69 & 74 & 46 \\
\hline Facility/individual who conducted the abortion & & & & \\
\hline Public sector or private sector (allopathic) & 93.8 & 94.2 & 94.6 & 95.7 \\
\hline Public sector & 6.3 & 11.6 & 9.5 & 4.4 \\
\hline District Hospital & 4.7 & 2.9 & 5.4 & 2.2 \\
\hline $\mathrm{PHC} / \mathrm{RH}$ & 1.6 & 8.7 & 4.1 & 2.2 \\
\hline Private sector (allopathic) & 87.5 & 82.6 & 85.1 & 91.3 \\
\hline Uncertified providers & 6.3 & 5.7 & 5.5 & 4.3 \\
\hline Nurse/ANM & 0.0 & 1.4 & 0.0 & 0.0 \\
\hline Chemist & 6.3 & 4.3 & 4.1 & 4.3 \\
\hline Dai/TBA ${ }^{1} /$ herbalist/other traditional practitioner & 0.0 & 0.0 & 1.4 & 0.0 \\
\hline Self/family member/friend & 0.0 & 0.0 & 0.0 & 0.0 \\
\hline Method of abortion used ${ }^{2}$ & & & & \\
\hline Surgery with general anaesthesia & 56.3 & $31.9^{* *}$ & 62.2 & $37.0^{* *}$ \\
\hline Surgery without general anaesthesia & 21.9 & 29.0 & 20.3 & 28.3 \\
\hline Pills (Medical abortion) & 15.6 & $37.7^{* *}$ & 6.8 & $32.6^{* *}$ \\
\hline Injections & 4.7 & 1.4 & 8.1 & 0.0 \\
\hline $\begin{array}{l}\text { Herbs/roots/foreign bodies/homemade concoction/ } \\
\text { Ayurvedic medicines }\end{array}$ & 1.6 & 0.0 & 2.7 & 2.2 \\
\hline
\end{tabular}

${ }^{*} p<=0.05 ;{ }^{* *} p<=0.01 ;{ }^{* * *} p<=0.001$

${ }^{1}$ Dai or TBA: traditional birth attendant.

${ }^{2}$ One woman in Jalna at endline reported that she did not know the method used.

same period. Notably, in both settings, percentages undergoing repeat abortions in rapid succession declined considerably: from 11 to 6 in Aurangabad and from 8 to 2 in Jalna.

Findings presented in Table 6.4 suggest that percentages of women who obtained post-abortion contraceptive counselling were far from universal at baseline and endline; however, there was an increase in percentages of women in Aurangabad who reported post-abortion contraceptive counselling (from 32 to 42), compared to a decline in percentages so reporting in Jalna (from 51 to 36). 


\section{Table 6.3}

Percentage of women reporting multiple and second trimester abortions, among women who underwent abortion in the three years preceding the interview, Aurangabad and Jalna districts, Maharashtra

\begin{tabular}{|c|c|c|c|c|}
\hline & \multicolumn{2}{|c|}{ Aurangabad } & \multicolumn{2}{|c|}{ Jalna } \\
\hline & Baseline & Endline & Baseline & Endline \\
\hline $\begin{array}{l}\text { Number of women who underwent an abortion in the three } \\
\text { years preceding the interview }\end{array}$ & 64 & 69 & 74 & 46 \\
\hline Women reporting second trimester abortion ${ }^{1}$ & 18.8 & 18.8 & 24.3 & 26.1 \\
\hline $\begin{array}{l}\text { Women reporting repeat abortions during the three years } \\
\text { preceding the interview }{ }^{1}\end{array}$ & 10.9 & 5.8 & 8.1 & 2.2 \\
\hline
\end{tabular}

${ }^{1}$ Differences between baseline and endline values are not significant.

\section{Table 6.4}

Percentage of women who received post-abortion contraception counselling, who adopted post-abortion contraception, and for whom the husband's consent was not required, among women who underwent abortion in the three years preceding the interview, Aurangabad and Jalna districts, Maharashtra

\begin{tabular}{|c|c|c|c|c|}
\hline & \multicolumn{2}{|c|}{ Aurangabad } & \multicolumn{2}{|c|}{ Jalna } \\
\hline & Baseline & Endline & Baseline & Endline \\
\hline $\begin{array}{l}\text { Number of women who underwent an abortion in the three } \\
\text { years preceding the interview }\end{array}$ & 64 & 69 & 74 & 46 \\
\hline Provider talked about post-abortion contraception & 31.7 & 42.4 & 50.7 & 36.4 \\
\hline Adopted post-abortion contraception & 51.6 & 52.2 & 54.1 & 45.7 \\
\hline Provider did not require husband's consent & 5.0 & $21.2^{* *}$ & 5.6 & 4.6 \\
\hline
\end{tabular}

${ }^{*} p<=0.05 ;{ }^{* *} p<=0.01 ;{ }^{* * *} p<=0.001$.

Nevertheless, there was little change across the intervention period in post-abortion contraception among women in Aurangabad, with percentages adopting contraception remaining steady at 52 at both baseline and endline; in Jalna, in contrast, there was a decline in post-abortion contraception (from 54\% to 46\%). Respect for women's rights was measured by way of percentages reporting that their husband's consent was not required for the abortion.
There was a significant increase in percentages of women in Aurangabad reporting that the provider had not required the consent of the husband: while just $5 \%$ so reported at baseline, at the time of the endline, as many as $21 \%$ reported that their husband's consent was not required for the abortion. In contrast, in Jalna, the percentage of women reporting that the provider did not require the husband's consent remained unchanged (5-6). 


\section{Summary}

The longer term objectives of the district-level CAC model were to increase women's use of abortion facilities in the public sector and reduce unsafe aspects of abortion, including delayed and repeat abortions, and hence findings shed light on progress made in the short period under observation in changing these practices, among women whose abortion took place in the three years preceding the baseline and endline interviews. By and large, findings confirm that changes have been modest but illustrative.

In total, $5-7 \%$ of women in Aurangabad and Jalna had experienced an abortion in the three years prior to the baseline and endline surveys, abortion ratios of 11-16, correspondingly, were observed. There was little change in the percentage of women reporting second trimester abortions, and a modest decline in repeat abortions in both districts. Although the majority of abortions continued to take place in private facilities, there was an encouraging increase in Aurangabad, compared to a small decline in Jalna, in percentages of women reporting that their last abortion had taken place in a public sector facility, and specifically, in a PHC or RH. Findings also suggest that there was an impressive shift from D\&C to MVA/MA, with the use of medical abortion increasing impressively in both districts.

In addition, percentages of women reporting post-abortion contraception remained unchanged in Aurangabad, despite an increase among those reporting post-abortion contraceptive counselling. In Jalna, in comparison, percentages of women reporting both post-abortion contraceptive counselling and post-abortion contraception declined between the baseline and endline surveys. Finally, the percentages of women reporting that the provider had not required the husband's consent increased significantly in Aurangabad but was unchanged in Jalna. While we are unable to establish the link, it is possible that the intervention's success in raising women's awareness of abortion-related issues has contributed in part to this change. 


\section{CHAPTER 7}

\section{Summary and conclusions}

This chapter summarises the major findings of the study and highlights key lessons learned for programming to increase access to comprehensive abortion care by implementing a model developed by Ipas, one of the seven members of the Consortium for Safe Abortions in India. The intervention was implemented in partnership with the Department of Health and Family Welfare, Government of Maharashtra.

\section{Summary}

The district-level Comprehensive Abortion Care model had several objectives. It focused on increasing the availability of services through extensive training of providers in public sector facilities and ensuring that facilities were equipped with the necessary infrastructure and equipment to enable the provision of abortion services. At the same time, the intervention aimed to increase awareness among women and communities, more generally, about abortion-related issues, including the conditions under which it is legal, women's right to access abortion, the methods of abortion available and the location of abortion services. Finally, the longer term objectives were to increase women's access to abortion in public sector facilities, and improve the experiences of abortion-seekers in terms of, for example, a reduction in second trimester and repeat abortions and a shift from D\&C to MVA and medical abortion. Longer term objectives in public sector facilities such as an increase in post-abortion contraceptive counselling and contraceptive uptake, a reduction in post-abortion complications, and an improvement in the quality of care experienced by abortion-seekers, are not assessed in this report.

The intervention was conducted in more than half of all public sector facilities and among the rural areas served by these facilities in one district of Maharashtra, Aurangabad. A quasiexperimental research design, with cross-sectional surveys undertaken in all PHCs and RHs, and in villages in which community level activities were conducted in the intervention district, Aurangabad and in a neighbouring control district, namely Jalna, prior to the implementation of the intervention and at its conclusion, was used to evaluate the effects of the intervention. Intervention activities were implemented in a phased manner, with facility-based activities conducted over a 24-month period (January 2008 to December 2009) and community-based activities over a 15-month period (October 2008 to December 2009). The evaluation focused on married women aged 15-39, that is, those most likely to have experienced a recent pregnancy, and was conducted among a total of 1,308 and 1,339 women in Aurangabad and Jalna, respectively, at the time of the baseline survey in 2007, and among 1,013 and 1,017 , respectively, at the time of the endline survey in 2010 .

Findings highlight that at the time of the baseline survey, the availability of abortion services was limited and women's access to abortion services was further compromised by a host of factors including poor awareness of their right to avail services, long distances to facilities and substantial costs. Also evident was the poor quality of abortion- 
related care. Given this context, and given the short duration of implementation, the changes achieved by the intervention are clearly significant.

\section{Facility-level effects}

Facility-level effects were measured largely by process indicators. Findings indicate that the intervention had a considerable effect on increasing the availability of safe abortion services in public sector facilities. Indeed, while at baseline, hardly any PHC and just two of nine RHs in Aurangabad provided abortion services, by endline, one-third of all PHCs and almost all RHs (13 of 14) were doing so. Increases in Jalna were far less spectacular: onequarter of all PHCs and four of the ten $\mathrm{RHs}$ were providing services at the time of the endline survey. Correspondingly, there was a far more striking increase in the availability of MTP-certified providers in Aurangabad than in Jalna: at the PHC level, for example, an increase of 41 and 22 percentage points, respectively. Not only were trained providers more likely to be available in Aurangabad, but increases in provider awareness about abortion and women's abortion-related rights were also more evident in Aurangabad than in Jalna: at the PHC level, awareness of the four key abortion-related issues increased by 20 percentage points in Aurangabad, compared to no change in Jalna.

The effect of the intervention was also evident in terms of improvements in the availability of functioning essential equipment required for the provision of abortion services at the PHC level. The availability of such equipment increased by 48 percentage points in Aurangabad compared to 30 percentage points in Jalna; essential equipment was available in all 14 RHs in Aurangabad at endline, compared to seven of the 10 RHs in Jalna. Finally, displays of IEC materials on the legality and availability of abortion in facilities were much more evident at endline than baseline in both settings, but again, the increase was far more evident in Aurangabad (from 6\% to 69\% of all PHCs, and from three to $12 \mathrm{RHs}$ ) than in Jalna (from $5 \%$ to $49 \%$, and from four to six, respectively).

Along with the increase in the number of facilities providing abortion, there was a considerable increase, in total, in the number of abortions conducted. For example, in the year preceding the endline assessment, PHCs in Aurangabad had conducted in total, 295 abortions in comparison to 148 in Jalna; even so, the total number of abortions conducted in PHCs in both Aurangabad and Jalna over the 12-month period preceding the endline survey averaged just 15 . The caseload over the year was, as expected, higher among RHs. While RHs in Jalna had conducted, in total, more abortions than had those in Aurangabad, the increase in the number of abortions performed in the year preceding the baseline and endline assessments, was far more impressive in Aurangabad than Jalna; even so, over the 12-month period preceding the endline survey, an average of 68 and 91 abortions had been conducted, respectively, in the RHs in Aurangabad and Jalna.

Findings also suggest that at the time of the endline assessment, all the facilities in Aurangabad had discarded the use of $\mathrm{D} \& \mathrm{C}$ for first trimester abortions; in contrast, one of the nine PHCs, and two of the four RHs in Jalna continued to use it. The use of medical abortion was also more 
pronounced in Aurangabad than in Jalna: 11 of the 28 facilities in Aurangabad offered medical abortion, compared to just two of the 13 in Jalna.

The intervention was implemented in slightly less than half of all PHCs in Aurangabad and a comparison of indicators in intervention and non-intervention PHCs in Aurangabad further underscores the role of the intervention. By the time of the endline survey, more than half of the intervention PHCs and all RHs were providing abortion services, compared to just one-quarter of the non-intervention PHCs and two of the three RHs. Likewise, the availability of trained providers, IEC materials and functioning essential equipment for the provision of abortion services were systematically more available in intervention than non-intervention facilities.

\section{Community-level effects}

Findings suggest that at the time of the endline survey, women in Aurangabad were considerably more likely than those in Jalna to have received messages through interpersonal contacts, group meetings, wall signs and street plays, concerning the legality of abortion, its availability in public sector facilities and the fact that pregnancy may be terminated using oral medication. In addition, findings show that there have been significant improvements in awareness, notably in the intervention district, between the time of the baseline and endline surveys. For example, awareness of medical abortion increased significantly (by 8 percentage points) in Aurangabad, but fell by 14 percentage points in Jalna. Awareness that abortion is available in public sector facilities also increased significantly (by 10 percentage points) in Aurangabad, but remained unchanged in Jalna. Awareness that abortion is available at the PHC/ $\mathrm{RH}$ level increased by 41 percentage points in Aurangabad, compared to 29 percentage points in Jalna. Awareness of at least one condition in which abortion is legally available increased significantly (by 13 percentage points) in Aurangabad, but fell (by 4 percentage points) in Jalna. At the same time, misperceptions that abortion is illegal in at least one valid condition fell in both settings-by 11 percentage points in Aurangabad and 8 percentage points in Jalna. Moreover, findings also highlight that the intervention had a significant positive net effect on most indicators reflecting women's awareness of abortion-related matters: awareness of surgical and medical abortion, and awareness that abortion is available in public sector facilities in general, and PHCs and RHs in particular. At the same time, the intervention had a significant negative net effect on misperceptions held about conditions under which abortion is legal. Indeed, the net effect of the intervention on reducing misperceptions was significant and negative in five of the seven conditions probed.

The longer term objectives of the districtlevel CAC model were to increase women's use of abortion facilities in the public sector and reduce unsafe aspects of abortion, including delayed and repeat abortions, and hence findings shed light on progress made in the short period under observation in changing these practices, among women whose abortion took place in the three years preceding the base and endline interviews. By and large, findings confirm that changes have been modest but illustrative. 
In total, $5-7 \%$ of women in Aurangabad and Jalna had experienced an abortion in the three years prior to the baseline and endline surveys; abortion ratios of 11-16, correspondingly, were observed. There was hardly any change in the percentage of women reporting second trimester abortions, and a modest decline, in repeat abortions in both districts. Although the majority of abortions continued to take place in private facilities, there was an encouraging increase in Aurangabad, compared to a small decline in Jalna, in percentages of women reporting that their last abortion had taken place in a public sector facility, and specifically, in a PHC or RH. Findings also suggest that there was an impressive shift from D\&C to MVA/MA, with the use of medical abortion increasing impressively in both districts. Improvements in uptake of postabortion contraception were not evident, although women in the intervention district were more likely than those in the control district to have received post-abortion contraceptive counselling; in comparison to the control district, however, percentages of women reporting both post-abortion contraception counselling and practice were higher in the intervention district at endline. Finally, there was a significant increase in the percentage of women in the intervention district, but not the control district, who reported that the provider had not required the husband's consent for the abortion.

\section{Limitations}

Our study has several limitations that may have affected the effects of the intervention. The most prominent of these is the duration of the intervention. The intervention was implemented over a short period of time: facility- and community- level activities were conducted over 24 and 15 months, respectively, during the period 2008 to 2009. This period included such start up activities as the establishment of a training site and training providers (each training activity lasted about three weeks and included no more than three medical officers), setting up a facility-monitoring mechanism, designing the BCC campaign, and identifying and partnering local NGOs to conduct the communitybased component. A 15 to 24 month period was likely insufficient to effect major changes, particularly those involving changes in practices (such as abortion-seeking in the second trimester, preference for private sector facilities). As a result, again, observed effects are likely to be conservative, and in some instances, for example, quality of care in public sector facilities and post-abortion contraception or morbidity among women undergoing abortion in public sector facilities, could not be assessed.

A second limitation is the possible diffusion of intervention effects into the control district. For example, training of providers and upgrading of facilities to enable the provision of abortion were extended, during the course of the project, to neighbouring districts including Jalna by the state government. At the same time, many women had been exposed to the Kalyani campaign, that is, the community level information-building activities of the intervention. And finally, there is some unsubstantiated information that some women from Jalna sought their abortion from a facility in Aurangabad. All of these factors may have reduced the net effect of the intervention, and the effects observed must therefore be acknowledged as conservative. 
Finally, we acknowledge that over the period of the intervention, substantial general health sector changes took place; for example the implementation of the National Rural Health Mission and the introduction of the Janani Suraksha Yojana, the inclusion of a new cadre of workers, namely the ASHAs, and liberalisation of medical abortion procedures to enable the provision of medical abortion at the PHC level if an appropriate referral facility is available. All of these programmatic changes may have influenced the availability of services and community-level awareness of abortion services in both districts. Thus, notwithstanding our efforts to distinguish the effect of the intervention after controlling for confounding factors, it may be difficult to attribute changes entirely to the intervention.

\section{Recommendations}

Several lessons can be drawn from the experience of implementing the Comprehensive Abortion Care model, which could be relevant for its modification and up-scaling. These are outlined below:

\section{Targeting the most-at-risk}

Findings have suggested that the awareness building component of the intervention succeeded in raising awareness of abortion-related matters. Nevertheless, awareness levels were far from universal or comprehensive. Evidence suggests that while community-level awareness building efforts are useful, they are not sufficient and messages need to be targeted to those most at risk of needing an abortion. One such group, easily available to the health sector, is women seeking other reproductive health services such as pregnancy-related care, contraception, or for concerns about menstruation and other sexual health matters. Efforts must be made to inform these women when they seek services (and those who accompany them if possible), about the availability of abortion should the need arise, the conditions under which it is legal and illegal, the methods by which it is conducted, and the public sector facilities in which it is available.

\section{Shifting preferences for abortion services to the public sector}

Findings have suggested that while awareness that public sector facilities provide abortion has increased considerably, and notwithstanding facility-level data on the large increase in the number of abortions conducted in the public sector in Aurangabad, the majority of women who underwent an abortion in the period between the baseline and endline surveys had continued to use private sector facilities and there was just a small shift towards the use of public sector abortion facilities in Aurangabad. Reasons for the continued preference for the private sector may include lack of awareness about the availability of abortion at peripheral public sector facilities, or perceptions about poor quality of services at public facility level, or the persistence of misperceptions at endline (albeit significant declines from baseline), with a large majority of women continuing to believe that the husband's (or guardian's) signature is mandatory for an abortion. It is important that the health system take steps to inform communities about the availability and quality of abortion services. 


\section{Extending interventions to the private sector}

Notwithstanding efforts to make abortion services available in the public sector, our evidence has underscored women's preferences for abortion in the private sector. It is clear that many aspects of service quality and quality of care remain overlooked in the private sector, including for example, respect for women's rights and emphasis on post-abortion contraceptive counselling. Models are needed that incorporate the private sector in the provision of abortion in rural areas, and ensure that the services provided are of good quality.

\section{Addressing post-abortion contraception concerns}

While post-abortion contraceptive counselling increased and was far more likely to be reported by women in the intervention than control site, it did not translate into a corresponding effect on the practice of post-abortion contraception. Models need to be generated that follow up women who have recently undergone abortion in order to reinforce counselling messages and address any concerns they may have about initiating or practising a method of contraception.

\section{Addressing the quality of abortion care}

Findings have highlighted the success of the intervention in raising awareness about quality of care among medical officers of PHCs and $\mathrm{RH}$ s as well as improving the quality of care delivered to women undergoing abortion and the readiness of health facilities to provide safe abortion services. This is perhaps one of the most significant aspects of the intervention. It is important now to ensure that women who avail of abortion services from public sector facilities do indeed experience care of good quality and respect for their reproductive rights; in this context, incorporating a component on quality of care and women's reproductive rights within abortion training programmes is central.

\section{Integration of facility- and community-based components}

Findings suggesting a disconnect between various facility- and community-based activities, highlight the need for greater integration between the facilitypreparedness and the demand generation processes. Health system outreach workers as well as NGO outreach workers must be made responsible, for example, for informing women about safe abortion, supporting those in need to reach an appropriate facility and following up those who have undergone an abortion to monitor side-effects and address postabortion contraception. At the same time, activities are needed that strengthen the capacity of nongovernmental organisations and other civil society mechanisms to monitor health system activities and demand the services that are due to communities.

In brief, the findings from this evaluation are encouraging in many respects. They suggest that the district-level CAC model that focuses on facility strengthening, provider training and community awareness building is a promising approach through which to enhance access of poor rural women to safe abortion. The intervention was feasible to implement and can be integrated into existing government services without much additional investment. 


\section{References}

Ashenfelter, O. 1978. "Estimating the effect of training programs on earnings", Review of Economics and Statistics 60(1):47-57.

Ashenfelter, O and D. Card. 1985. "Using the longitudinal structure of earnings to estimate the effect of training programs", Review of Economics and Statistics 67(4):648-60.

Barge, S., M. E. Khan, S. Rajagopal et al. 1998. "Availability and quality of MTP services in Gujarat, Maharashtra, Tamil Nadu and Uttar Pradesh," Paper presented at the Global Meeting on Post-abortion Care and Operations Research, organised by Population Council, New York.

Barge, S., H. Bracken, B. Elul et al. 2004. Formal and Informal Abortion Services in Rajasthan, India: Results of a Situation Analysis. New Delhi: Population Council.

Barua, A. and H. Apte. 2007. "Quality of abortion care: perspectives of clients and providers in Jharkhand," Economic and Political Weekly 42(48):71-80.

Chhabra, R. and S.C. Nuna. 1994. Abortion in India: An Overview. New Delhi: Ford Foundation.

Duggal, R. and S. Barge. 2004. "Abortion services in India: Report of a multicentric enquiry". Abortion Assessment Project-India. Mumbai: CEHAT/Healthwatch.

Elul, B., S. Barge, S. Verma et al. 2004. Unwanted Pregnancy and Induced Abortion: Data from Men and Women in Rajasthan, India: Report. New Delhi: Population Council.

Ganatra, B. R. 2000. "Abortion research in India: What we know and what we need to know," in Women's Reproductive Health in India, eds. R. Ramasubban and S. Jejeebhoy. Jaipur: Rawat Publications.

Ganatra, B. R., S. Hirve, S. Karvande et al. 2008. "Induced abortions in rural western Maharashtra: Prevalence and patterns," in Reproductive Health in India: New Evidence, eds. M. Koenig, S. Jejeebhoy, J. Cleland and B. Ganatra. New Delhi: Rawat Publications.

Government of India. 1971. The Medical Termination of Pregnancy Act (Act. No. 34). New Delhi: Government of India.

Government of India. 2003. The Medical Termination of Pregnancy Rules (Amendment). New Delhi: Government of India.

International Institute for Population Sciences (IIPS). 2006. District Level Household Survey (DLHS-2), 2002-04: India. Mumbai: IIPS.

International Institute for Population Sciences (IIPS) and ORC Macro. 2000. National Family Health Survey (NFHS-2), 1998-99: India. Mumbai: IIPS. 
International Institute for Population Sciences (IIPS) and Population Council. 2010. Youth in India: Situation and Needs, 2006-2007. Mumbai: IIPS.

Jejeebhoy S. J., A. J. F. Zavier and S. Kalyanwala. 2010. Assessing Abortion-related Experiences and Needs in Four Districts of Maharashtra and Rajasthan, 2006. New Delhi: Population Council.

Kalyanwala, S., A. J. F. Zavier and S. Jejeebhoy. 2010. Public Health Facilities and Women's Access to Abortion: A Situation Analysis in Maharashtra and Rajasthan. New Delhi: Population Council (unpublished report).

Malhotra, A., L. Nyblade, S. Parasuraman et al. 2003. Realizing Reproductive Choice and Rights: Abortion and Contraception in India. Report. Washington DC: International Council for Research on Women.

Ministry of Health and Family Welfare (MOHFW). 2000. National Population Policy 2000. New Delhi: Department of Family Welfare, MOHFW, Government of India.

Ministry of Health and Family Welfare (MOHFW). 2001. Guidelines for Medical Officers for Medical Termination of Pregnancy upto eight weeks using Manual Vacuum Aspiration Technique. New Delhi: Maternal Health Division, MOHFW, Government of India.

Ministry of Health and Family Welfare (MOHFW). 2005. National Rural Health Mission: Meeting People's Health Needs, Framework for Implementation 2005-2012. New Delhi: MOHFW, Government of India.

Ministry of Health and Family Welfare (MOHFW). 2010. Annual Report 2009-10. New Delhi: Department of Health and Family Welfare, MOHFW, Government of India.

Office of the Registrar General, India (RGI). 2006. Sample Registration System, Maternal Mortality in India: 1997-2003 Trends, Series I, Causes and Risk Factors. New Delhi: RGI.

Office of the Registrar General and Census Commissioner. 2004. Primary Census Abstract: Total Population: Table A-5. New Delhi: Office of the Registrar General and Census Commissioner.

Saha, S., R. Duggal and M. Mishra. 2004. Abortion in Maharashtra: Incidence, Care and Cost. Abortion Assessment Project India. Mumbai: CEHAT/Healthwatch.

World Health Organization. 2003. Safe Abortion: Technical and Policy Guidance for Health Systems. Geneva, World Health Organization. 



\section{Population Council}

Zone 5-A, Ground Floor India Habitat Centre Lodi Road

New Delhi 110 003, India 